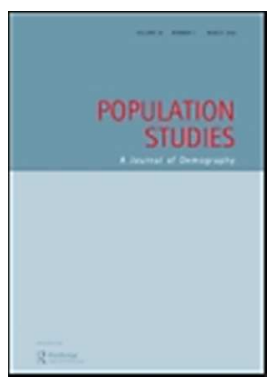

\title{
Worldwide fertility declines do not rely on stopping at ideal
} parities

\begin{tabular}{|r|l|}
\hline Journal: & Population Studies \\
\hline Manuscript ID & RPST-2018-1685.R1 \\
\hline Manuscript Type: & Original Paper \\
\hline Keywords: & $\begin{array}{l}\text { fertility transition, demographic transition, mixture model, parity- } \\
\text { dependent, gamma-poisson, parity-independent, postponement, spacing }\end{array}$ \\
\hline
\end{tabular}

SCHOLARONE ${ }^{\text {m }}$

Manuscripts 


\title{
Corresponding Author:
}

Daniel J. Hruschka

School of Human Evolution and Social Change,

Arizona State University, Tempe, AZ, 85287

480-965-3087

Daniel.hruschka@asu.edu

\section{Worldwide fertility declines do not rely on stopping at ideal parities}

\author{
Daniel J. Hruschka ${ }^{1}$ \\ Rebecca Sear ${ }^{2}$ \\ Joseph Hackman ${ }^{1}$ \\ Alexandria Drake ${ }^{1}$ \\ ${ }^{1}$ School of Human Evolution and Social Change, Arizona State University, Tempe, AZ, 85287 \\ ${ }^{1}$ Department of Population Health, London School of Tropical Medicine and Hygiene, London, \\ UK, WC1E 7HT
}

Short Title: Fertility declines and ideal parities

Acknowledgments. We are grateful to Heidi Colleran, Gert Stulp, and Mary Towner for constructive feedback on earlier versions of the paper. The work was supported by the National Science Foundation grant BCS-1150813, jointly funded by Programs in Cultural Anthropology, Social Psychology Program and Decision, Risk, and Management Sciences; and BCS-1658766, jointly funded by Programs in Cultural Anthropology and Methodology, Measurement and Statistics. The funder had no role in study design, data collection and analysis, decision to publish, or preparation of the manuscript. 


\begin{abstract}
A key demographic hypothesis has been that fertility declines rely on stopping at target parities, but emerging evidence suggests that women frequently reduce fertility without specific numeric targets. To assess the relative importance of these two paths to fertility decline, we develop a novel mixture model to estimate: (1) the proportion of a sample that stopped at a target parity and (2) the mean completed fertility among those who did not. Applied to Demographic and Health Survey data from women (ages 45-49) in 84 low- and middle-income countries as well as U.S. census cohorts, this model shows considerable variation in the proportion stopping at specific parities (1\%-84\%). These estimates also suggest that declines in completed fertility are largely attributed to women who did not stop at target parities. This suggests that stopping at ideal parities may be less important than parityindependent decisions for a wide range of fertility transitions.
\end{abstract}

Key Words: Fertility transition, demographic transition, mixture model, parity-dependent, gamma-poisson, parity-independent 


\section{Introduction}

In the last several centuries, human populations worldwide have witnessed a dramatic reduction in fertility. While the decline is empirically well-established, there is still considerable debate about the specific cultural, social, and psychological factors driving this change. A key point of controversy surrounds the role played in the decline by women and couples aiming for specific ideal parities. In an influential formulation of preconditions for the fertility transition, the economist and demographer A.J. Coale proposed that a requirement for fertility decline is a cognitive shift whereby reproduction moves into the realm of "conscious calculation" (Coale 1973). Demographers have often interpreted this shift to conscious choice as a cognitive change toward specific numeric goals or targets (e.g., 2 children) accompanied by limiting fertility after an ideal completed fertility has been achieved (Henry 1961; Knodel 1983; Van de Walle 1992; Reher and Sanz-Gimeno 2007). According to this first perspective, the major force behind fertility decline is an increasing focus on achieving one of a limited number of low fertility targets (e.g. 2 children, 3 children, or 4 children). Indeed, a long-stated assumption in the demographic literature is that controlling fertility through parity-specific stopping has a greater impact on fertility rates than other means of regulating reproduction, such as spacing or postponement (Van de Walle 1992; Westoff and Bankole 2000; Cleland et al. 2006; Van Lith et al. 2013).

Numerous studies of historical Europe have been interpreted to support this view (Knodel 1979, 1987; Hionidou 1998; Reher and Sanz-Gimeno 2007). However, in the last two decades, converging lines of evidence challenged the primacy of parity-specific stopping in driving down fertility. Ethnographic research, largely based in Sub-Saharan Africa, suggests that Hruschka-3 
a great deal of strategic decision-making focuses on maintaining appropriate timing of births and ensuring the possibility for future reproduction rather than on the absolute number of children (Mason 1997; Bledsoe et al. 1998; Bledsoe and Banja 2002; Johnson-Hanks 2002, 2007). If this is the case, the existence of non-numeric responses to ideal family size (e.g. "Only god knows" or "Don't know") in many low and middle income countries may not reflect a lack of concern about regulating fertility, but rather a lack of concern about specific numeric targets (Knodel and Van de Walle 1979; Hayford and Agadjanian 2011). In such situations, we might expect decisions about other aspects of reproduction, such as spacing, postponement, and later starts to play a greater role in fertility decline than stopping based on a specific achieved parity (Moultrie et al. 2012; Timæus and Moultrie 2013; Casterline and Odden 2016b, 2016a).

As Van Bavel notes, quantitative demography has traditionally focused on parity-specific stopping in part due to the early development of analytical tools for assessing parity-specific stopping (Coale and Trussell 1974; David et al. 1988; Van Bavel 2004b). However, in the last two decades, quantitative demographers have also developed a number of tools to demonstrate that fertility declines in a number of specific settings have involved a combination of both parity-specific stopping and increases in spacing and postponement (Anderton and Bean 1985; Knodel 1987; Feng et al. 1995; Hionidou 1998; Szreter and Garrett 2000; Van Bavel 2004a; Timæus and Moultrie 2008; Van Bavel and Kok 2010; Timæus and Moultrie 2013). Changing timing of births can arise for a number of reasons, including birth spacing focused on the interval between one birth and the next, a later start of first reproduction, stopping for reasons other than current parity, and postponing for reasons unrelated to the age of the last 
child or the total number of children (Timæus and Moultrie 2013; Casterline and Odden 2016b; Towner et al. 2016; Mattison et al. 2018).

Current approaches to estimating parity-independent strategies have two significant limitations, however. First, most current models demand data that is not always present across a wide range of settings, making it difficult to generalize or to examine broad ecological influences on these fertility patterns. Although a number of ethnographic, historical, and quantitative case studies demonstrate the potential importance of fertility control without ideal family sizes (Knodel 1987; Van Bavel 2004a), it is not clear how widespread the phenomenon is or how important it is for recent fertility declines compared to parity-specific stopping.

Methods that can be used across a broad range of datasets are crucial for directly comparing, for example, how recent (and relatively fast) fertility transitions in Asia and Africa might differ from the slower transitions observed in historical Europe. Second, current methods estimate the degree of parity-specific stopping as well as parity-independent spacing and postponement for entire populations. However, it is likely that any population consists of some mixture of women who have stopped at a specific target and others who are regulating fertility based on other criteria. If this is the case, estimates from current methods potentially confound two very different kinds of decision-making. Thus, to model gradual change within populations, as has happened in many fertility transitions, it is likely important to track changing mixtures of strategies as well.

To estimate the importance of an increasing focus on numeric targets relative to other strategies for regulating reproduction in modern fertility declines, we analyse completed fertility data from two data sources: (1) 301 Demographic and Health Surveys (DHS) taken Hruschka-5 
between 1985 to 2016 across 84 low- and middle-income countries at varying stages of fertility transitions and (2) $20^{\text {th }}$ century historical census data from the U.S (ICF International 19912014; Ruggles et al. 2015). The DHS datasets provide global, but temporally shallow, data on recent variation in fertility outcomes. These represent populations in Europe and Central Asia $(n=20)$, South Asia $(n=23)$, sub-Saharan Africa $(n=163)$, North Africa and Middle East $(n=21)$, Southeast Asia $(n=22)$, and Latin America and Caribbean $(n=52)$. Most DHS datasets also include detailed information on the timing of births for each woman. This permits comparison of our population-based model estimates with micro-level data on birth timing. The U.S. data complements the temporally shallow DHS datasets by illustrating how the model detects changes over long-term historical time without the benefit of such micro-level data.

The analyses presented here rely on a novel extension of zero-inflated regressions to decompose sample distributions of completed fertility into: (1) the proportion of the population that ended fertility at specific low numeric targets and (2) and the lifetime rates of reproduction (e.g. mean completed fertility) among the complementary proportion that does not stop at a specific numeric target. The model is an effort to estimate the approximate proportion of the population completing lifetime reproduction in one of two ways. It is very possible that over the course of a lifetime, a woman may move between these two approaches. As examples, a woman who ultimately stops at a desired target parity, may have followed any number of strategies to achieve that parity, including postponing births and spacing births based on current parity. A woman who starts with a specific parity in mind, may change to another preferred parity later in life, or move away from a parity preference all together. Finally, women in either of these broad categories may use a wide range of strategies to 
accomplish their goals during the course of their reproductive life (Kingsley 1963). The crucial distinction between parity-specific stopping and parity-independent decisions, is that parityspecific stopping is defined by ending lifetime reproduction at a specific number of children based on a desire for that number of children. The model described here is to estimate the relative mixture of distributions generated by these two kinds of decision-making.

In the following sections we (1) present our model verbally, illustrated with some examples; (2) describe in detail the methodology; (3) assess how well our population -level model performs against micro-level data, by assessing whether our estimate of parity-specific stopping correlates with two indicators from birth records across 301 Demographic and Health Surveys; (4) examine how variation in our two key estimates -the proportion parity-specific stoppers and the mean rate among those following a parity-independent approach-are associated with fertility decline; (5) compare the relative importance of these two strategies for fertility decline across different world regions.

\section{A Verbal Description of the Model}

The model we use here assumes that to a first approximation individuals can follow one of two approaches to lifetime reproduction. The first approach, which we call the parity-independent approach, relies on behavioural management as well as physiological constraints on the timing of births, rather than on achievement of a specific ideal number of children. The pace and timing of births can arise from a number of factors, including timing of first reproduction, extending reproduction based on the age of one's youngest child, postponing for other reasons, and even stopping (as long as it does not depend on achieving a specific parity). Thus, 
there are multiple variants of this approach, including both the use of spacing and postponement (Timæus and Moultrie 2008, 2013; Casterline and Odden 2016b). The unifying feature of this approach is that a woman following this approach disregards current parity in decisions to end fertility, a mode of decision-making that has been observed in a number of ethnographic and historical examples (Bledsoe and Banja 2002; Johnson-Hanks 2002; Van Bavel 2004a; Timæus and Moultrie 2008). Parity-independent fertility can include substantial variation within individuals, such as increasing birth intervals with age. It can also include substantial variation between individuals, such as variation in average interbirth intervals as well as varying windows of opportunity for reproduction defined by the onset of puberty and menopause. Importantly, many of these diverse sources of variation in pace, timing, and postponement will lead to completed fertility distributions approximating a mixture of Poisson distributions (Winkelmann 1995). As an example, the model does not require a constant rate of reproduction across an individual women's life, since a population with a time-varying rate of reproduction (e.g. increasing birth intervals with age) can still produce a Poisson mixture distribution of completed fertility (Winkelmann 1995). Moreover, a population with variation in window of opportunities for reproduction and average interbirth intervals will also produce a mixture of Poisson distributions with varying lifetime rates. Thus, many kinds of parityindependent strategies can result in distributions that look like a mixture of Poisson distributions.

We model this mixture of Poisson processes as a Gamma-Poisson or negative binomial model (Brass 1958; Wood 1994). Figure 1a, illustrates a sample from Bangladesh in 1996 (women ages 45-49) for which the predicted distribution from such a process is a close 
approximation to the observed distribution of completed fertility. An important point about such distributions is that they can be summarized completely by two parameters: an average lifetime rate of reproduction and the variance of lifetime rates between women in the population. The lifetime rate of reproduction is how many children a woman is expected to bear over a lifetime. However, under a count process (e.g. a Poisson process) the realized completed fertility for a specific woman will not perfectly reflect a lifetime rate because of stochastic variation introduced by the count process (Hruschka and Burger 2016). Thus, the rates estimated for a Poisson process reflect a summary measure of a stochastic process, and not some "master schedule" of planned interval lengths (Bongaarts and Potter 2013). It is also important to emphasize that the estimation of a mean lifetime rate for a population does not assume that women follow a constant rate over the life course. For example, if age-specific fertilities decline over the life course, the estimated lifetime rate would represent an average over age-specific rates. Notably, as long as women are not stopping at specific parities, continuously declining age-specific fertilities would still produce a Poisson mixture distribution of the kind used in this model (Winkelmann 1995)

The second, parity-specific stopping approach targets a specific set of ideal parities, and then stops or severely limits reproduction when such parities are reached (Henry 1961; Coale 1973). A woman or a couple might have several possible ideal parities (e.g. 2 or 3 children) that may vary over the life-course with varying weights on how important each is (Coombs 1974). However, women or couples following the parity-specific approach will tend to stop reproduction within that small set of ideal parities. Prior to achieving the desired parity, a woman may follow any number of strategies to achieve that parity, including changing the 
timing of births. However, it is not necessary that this follows a "master schedule" with preplanned intervals to achieve a specific parity (Bongaarts and Potter 2013). The crucial distinction between parity-specific stopping and parity-independent fertility, is that in the former there is a clear stopping rule for the number of children. We assume here that when people set specific ideal parities, that they are most likely in the low range of fertility (i.e. zero to five children), with some probability assigned to each of these outcomes. As we will show later, estimated parity-specific stopping is almost exclusively concentrated at 1 to 3 (and to a lesser extent 4) across all samples. Nonetheless, 5 is still included as a potential target in the models to provide a check on the need for parities above 4 as potential targets. Ultimately, model estimates indicate that 5 is almost never a target for parity-specific stopping. We also treat nulliparity as a special case of parity-specific stopping as it can reflect either lifetime infertility or a choice to remain nulliparous.

An example of a situation where a substantial portion of the population is likely to be following parity-specific stopping is the Kazakhstan 1995 DHS sample (Figure 1b and 1c). A pure gamma-poisson does not closely approximate the empirical distribution, because the distribution is too peaked at low parities (Figure 1b). When we permit some proportion of the women to engage in parity-specific stopping at parities 0 to 5 , we can then also estimate the gamma-poisson distribution of fertility among the complementary set of women following a parity-independent approach (illustrated by the dotted line in Figure 1c). Importantly, in this sample, some proportion of the women arrived at low parities via parity-specific stopping (the proportion of over the dotted line in Figure $1 \mathrm{c}$ for parities 0 to 5 ), while others arrived at low parities via a parity-independent approach (the proportion under the dotted line in Figure 1c). 
At parities higher than 5, the gamma-poisson applied to the subset of women following a parity-independent approach provides an excellent fit to the empirical distribution. Figure 1d illustrates a situation where nearly all women are stopping at specific parities (Ukraine 2007 DHS). Nearly all cases are between 1 and 3, and there are so few cases above five that a parityindependent approach is very unlikely to have generated much of this distribution of completed fertilities. See supplementary materials for comparable figures for all samples in the current study.

According to the model, the observed lifetime fertility for any one person might have arisen from either parity-specific stopping or from stochastic events during a Poisson-like process of reproduction. This raises the need to model the distribution of completed fertilities as a statistical mixture of the two approaches. Using an extension of classical zero-inflated regression models, we describe a method to estimate from a distribution of completed fertility: (1) the proportion of women following a parity-independent vs. parity-specific stopping approach in a given sample, and (2) the mean lifetime rates among women following a parityindependent approach.

\section{Materials and Methods}

Samples. We use data from two sources - international Demographic and Health Surveys (DHS) to examine diversity across contemporary populations (1985-2016) and historical U.S. censuses to examine long-term change (cohorts from 1940-1990 censuses) (ICF International 1991-2014; 
Ruggles et al. 2015). First, we analyse 301 DHS across 84 low- to middle-income countries that have collected systematic, comparable data on women's reproductive histories (Arnold 1990). We focus on women for two practical reasons. First, the DHS have primarily aimed their data collection efforts at women and children, and relatively few have collected comparable data for men. Second, even for DHS datasets that have information about male marital fertility, varying opportunities for extra-marital fertility make it impossible to estimate male fertility in the same way we assess female fertility. We consider DHS surveys collected between 1985 and 2016 that include information about fertility and household wealth. To assess the sensitivity of our findings to alternative samples of women, we also analyse and report in supplementary materials model estimates for ever-married women and living children.

Second, we analyse data from unweighted subsamples of 6 consecutive U.S. censuses (1940 1\% flat sample, 1950 1\%, 1960 1\%, 1970 1\%, 1980 5\%, and 1990 unweighted 1\%) archived by the Integrated Public Use Microdata Series at the Minnesota Population data center (Ruggles et al. 2015). To maintain comparability across census years that sometimes only collected fertility for ever-married women, we exclude never-married women from the US Census analyses. We also excluded women with imputed values for number of children ever born and for marital status. To control for changing ethnicity distributions over the $20^{\text {th }}$ century in the US, we focus on white, non-Hispanic women (Stulp et al. 2016). Due to slow estimation with very large sample sizes, for samples larger than 5000, we use a random subsample of size 5000 for estimation of each sample. The list of samples accompanied by key indicators and model estimates are provided in supplemental materials. 
In analyses of all samples, we examine estimates of completed fertility for women aged 45-49 as total live born children, as this is the measure that is uniformly available across all censuses and surveys (Eijkemans et al. 2014). In the most comprehensive study to date of six natural fertility populations in Europe and North America, $90 \%$ of women ended reproduction by 45 y and nearly $100 \%$ by 50 y. Thus, focusing on $45-49$ year olds will capture most live births. For the U.S. census, to fill in the time series, we also independently analysed cohorts of older samples of women (50-54y) for a total of 12 independent samples ( 6 census by 2 age categories per census).

Model Specification. In line with past work in fertility, the modeling approach aims to infer general patterns of decision-making in a population from aggregate distributions of fertility outcomes (Coale and Trussell 1974; Knodel 1977; David et al. 1988; Van Bavel 2004b; Timæus and Moultrie 2008). Compared to these approaches, the current approach has the advantage of requiring only the distribution of completed fertility in a population. Moreover, it provides a straightforward way of estimating how key parameters (e.g. proportion following a rate-based approach, and mean rate among those) depend on different factors (education, wealth, rural residence).

The model is related to multiple-hurdle models of fertility (Miranda 2010). However, it does not assume, as multiple-hurdle models do, that all women who have arrived at a specific final parity got there from a single strategy. Rather, a women who has a final parity of 2 may have reached that through parity-specific stopping or instead through a parity-independent 
Poisson process. Thus, the model is more closely aligned with a zero-inflated model, but permits inflation at other parities as well (Poston Jr and McKibben 2003). We treat nulliparousstopping as a special case of parity-specific stopping as it can potentially reflect either a decision to stop at 0 or life-long infertility. Thus, according to the model, there is some probability, $\mathrm{q}_{0}$, that someone will be nulliparous for either of these two reasons. There is an additional probability, $\mathrm{q}_{P L}$, that someone will have parities 1 through 5 due to parity-specific stopping. Of those parity-specific stopping at 1 through 5 , the probability of having parity y is $\mathrm{q}_{y}$. Although we will show that 5 children is generally never estimated to be a target we include it to assess the degree to which parity-specific stopping may extend to such high parities. In the event that parity-specific stopping is concentrated at lower parities, the estimates for $\mathrm{q}_{5}$, and possibly $\mathrm{q}_{4}$, should be statistically 0 .

Finally, there is the complementary probability, $1-\mathrm{q}_{0}-\mathrm{q}_{P L}$, that a person is following a parity-independent strategy. Among those following a parity-independent approach, the probability of parity $y$ is a gamma mixture of Poisson processes with mean lifetime rate, $\lambda$, and variance of lifetime rates, $\frac{\lambda^{2}}{\theta}$.

Here, we label the probability of achieving parity y through the parity-independent process as $\operatorname{PDF}(y \mid \lambda, \theta)$. The full probability can be written as:

$$
p(y)= \begin{cases}\left(1-\mathrm{q}_{0}-\mathrm{q}_{P L}\right) \times P D F(0 \mid \lambda, \theta)+\mathrm{q}_{0} & \text { if } y=0 \\ \left(1-\mathrm{q}_{0}-\mathrm{q}_{P L}\right) \times P D F(y \mid \lambda, \theta)+\mathrm{q}_{P L} \mathrm{q}_{y} & \text { if } y=1,2,3,4,5 \\ \left(1-\mathrm{q}_{0}-\mathrm{q}_{P L}\right) \times P D F(y \mid \lambda, \theta) & \text { if } y>5 \text { and }<20 \\ \left(1-\mathrm{q}_{0}-\mathrm{q}_{P L}\right) \times P D F(y \geq 20 \mid \lambda, \theta) & \text { if } y \geq 20\end{cases}
$$


Given that some datasets in the U.S. census have a single category of 12 or more births, in the U.S. census samples, we model a maximum of 12 births instead of 20 as a single category. We assume weakly informative prior distributions for the two gamma-poisson parameters as $\lambda \sim \operatorname{gamma}(3,0.5)$, which has an expected value of 6 children and a wide variance around that, and $\theta \sim \operatorname{gamma}(0.001,0.001)$, a commonly used weakly informative prior for the shape parameter for negative binomial distributions.

The probabilities of excess nulliparity, $q_{0}$, and of excess parities due to parity-specific stopping, $\mathrm{q}_{P L}$, are parametrized with binomial logistic models:

$q_{0}=\frac{\exp \left(\beta_{0}\right)}{1+\exp \left(\beta_{0}\right)} \quad$ and $\quad q_{P L}=\frac{\exp \left(\beta_{P L}\right)}{1+\exp \left(\beta_{P L}\right)}$

The probabilities of stopping at specific parities, $\mathrm{q}_{1}, \mathrm{q}_{2}, \mathrm{q}_{3}, \mathrm{q}_{4}, \mathrm{q}_{5}$, are modeled as a multinomial logistic with primaparity as the reference category.

$q_{i}=\frac{\exp \left(\beta_{i}\right)}{\exp \left(\beta_{1}\right)+\exp \left(\beta_{2}\right)+\exp \left(\beta_{3}\right)+\exp \left(\beta_{4}\right)+\exp \left(\beta_{5}\right)} \quad i=1,2,3,4,5 \quad \beta_{1}=0$ We assume uniform priors for $\beta_{0}, \beta_{P L}, \beta_{1}, \beta_{2}, \beta_{3}, \beta_{4}, \beta_{5} \sim \operatorname{logistic}(0,1)$ that are symmetric for $\beta_{1}, \beta_{2}, \beta_{3}, \beta_{4}, \beta_{5}$ by constraining $\beta_{1}+\beta_{2}+\beta_{3}+\beta_{4}+\beta_{5}=0$.

Model Estimation: We calculate parameter point estimates and credibility intervals from the estimated posterior probability distribution for the model. To estimate the posterior probability distribution, we use a Metropolis Hastings Markov Chain Monte Carlo process 
implemented in R (code available from authors). Depending on the convergence of estimates, we used a "short" or "long" estimation process. The first phase of the process tunes the proposal distribution with 40 (500 for "long" runs) tuning loops of 1000 iterations each. After each loop, the proposal distribution's scale is adjusted based on the acceptance rate from the prior 1000 iterations, and the proposal distribution's covariance structure is estimated from the previous 1000 iterations. With the final proposal distribution, we then allow 20000 steps for burn in (100000 for "long" runs) and then estimate the posterior distribution with 200000 steps (1000000 for "long" runs).

To ensure the Markov chain was well-mixed, we assessed stationarity of the Markov chain for each of the eight parameters by using a geweke test comparing the last $50 \%$ of iterations with the first $10 \%$ of iterations (Geweke 1991). Within each chain, we used a Bonferroni-corrected alpha to reject the null of no difference (alpha $=0.5 / 8$ for eight parameters). We also assessed whether the effective sample size for the run was less than 100, which would indicate the estimates are relatively unreliable using the coda package in $\mathrm{R}$ (Plummer et al. 2006). We applied "short" runs to the DHS datasets, but given high rates of non-convergence in the U.S. census samples ( > 15\%) with the "short" runs, we applied the "Iong" runs to all U.S. census samples. In those rare cases where chain diagnostics indicated a problem on the first run ( 3 for DHS, 0 for US), we re-estimated with a "long" run. In no cases did we need to re-run the analyses more than twice.

To assess the reliability of the estimation process, we also ran duplicate MCMC chains for all samples and compared duplicates. Key parameters estimates (e.g., $q_{P L}, \lambda, \theta$ ) were highly correlated across the two runs $(r>0.95)$. We calculate point estimates for each parameter as Hruschka-16 
the mean of the estimated posterior distribution for that parameter, and the $95 \%$ credibility interval as the $2.75 \%$ and $97.5 \%$ percentiles of the posterior distribution.

Fitting the Model to Survey Data: We fit the model to the completed fertility distribution in each of 301 DHS surveys as well as 12 U.S. census subsamples to estimate: (1) the excess proportion of nulliparous women $\left(q_{0}\right),(2)$ the proportion of women engaged in parity-specific stopping (at parities 1 to 5$)\left(q_{P L}\right)$ and (3) the mean $(\lambda)$ and variance of lifetime rate $\left(\frac{\lambda^{2}}{\theta}\right)$ among women not following parity-specific stopping. Among those women estimated to have stopped at specific target parities, we also report estimates of the proportion stopping at 1,2,3,4, and 5 children. For each of the 313 samples, we tested whether the sample's empirical distribution was different from the fitted model distribution using a chi-square test. The reference distribution for the chi-square statistic was generated with 50000 replicate samples drawn from the model distribution (using the Holm-Bonferroni method with alpha $=0.05,313$ tests) (R Core Team 2014). For those samples whose predictions significantly deviate from observations, we report the average deviation of predictions from observations. To assess whether standard pure gamma-poisson would also create comparable fits, we estimated the fit of an uninflated gamma-poisson model to the same 313 samples using the same chi-square test.

Comparing Estimates with Micro-level Data: We then assess how well the model estimate of parity-specific stopping correlates with two indicators from birth records estimated across 301 Demographic and Health Surveys. The first indicator is the concavity of parity progression 
ratios over increasing parity which has been used as a measure of the degree of parity-specific limitation (Brass et al. 1997). The second indicator-variance in parity-specific median intervals-examines how far a population's birth intervals deviate from the Poisson model's assumption of a constant median birth interval across parities. Specifically, we use the variance in median inter-birth interval length across the first five birth intervals ( 1 to 2,2 to 3,3 to 4,4 to 5 , and 5 to 6$)$. As an example, a population with completely constant median birth intervals between births 1 and 5 would have a variance of 0 , and any deviation from this uniform median birth interval would lead to increasing variance. Comparisons with birth records excluded 32 surveys which did not collect birth records, and two countries that contained only partial birth records (El Salvador 1985 and Tanzania 2012).

\begin{abstract}
Assessing sensitivity to different fertility measures and samples: We assessed the sensitivity of estimates when applying the model to alternative samples (e.g. ever married women 45-49 y) and measures (living children vs. liveborn children) in the DHS surveys.
\end{abstract}

\begin{abstract}
Assessing associations of parity-specific stopping and parity-independent rates with fertility declines: To assess the relationship of different strategies to variables traditionally associated with fertility declines, we estimate how sample estimates of key model outputs-proportion who stopped at specific target parities, and completed fertility among those following a parityindependent approach-correlate with sample characteristics traditionally associated with fertility declines. These include the entire sample's completed fertility, the proportion of
\end{abstract}


women with at least primary education, proportion of women with at least secondary education, and mean household wealth (estimated according to (Hruschka et al. 2015)).

To assess the degree to which each of these two strategies contributes to fertility decline in the DHS samples, we examine pairs of surveys from countries that exhibited more than a 0.5 child decline between the first and final surveys. We then estimate the expected decline in fertility in each of two idealized situations:

(1) Decline resulted purely from increasing parity-specific stopping. Here we assume the proportion of women engaged in parity-specific stopping $\left(\mathrm{q}_{P S}=\mathrm{q}_{0}+\mathrm{q}_{P L}\right)$ and their expected parity followed the observed decline between surveys, but everything else stayed the same.

(2) Decline resulted purely from changes in completed fertility among women following parity-independent strategies. Here we assumed the mean completed fertility among the parity-independent segment followed the observed decline between surveys, but everything else stayed the same

To estimate these expected values, we decompose completed fertility as $\mathrm{q}_{P S} M_{P S}+q_{P I} M_{P I}$, where $\mathrm{q}_{P S}$ and $q_{P I}$ are the proportion following parity-specific stopping and a parityindependent approach respectively, and $M_{P L}$ and $M_{P I}$ are the corresponding average completed fertilities of these two populations.

We estimate the decline in situation 1 as $\mathrm{q}_{P S}{ }^{\prime} M_{P S}{ }^{\prime}+q_{P I}{ }^{\prime} M_{P I}-\left(\mathrm{q}_{P S} M_{P S}+q_{P I} M_{P I}\right)$, where $\mathrm{q}_{P S^{\prime}}{ }^{\prime}, M_{P S}^{\prime}$ and $q_{P I}{ }^{\prime}$ are estimates from the second time point, and all others variables are estimates from the first time point. Here, $\mathrm{q}_{P S}{ }^{\prime} M_{P S}{ }^{\prime}+q_{P I}{ }^{\prime} M_{P I}$ is the hypothetical completed 
fertility at the second survey if the only variables to change between surveys were the proportion of women following parity-specific stopping vs. a parity-independent approach as well as the distribution of ideal family sizes among women following parity-specific stopping.

Similarly, we estimate the decline in situation 2 as $\mathrm{q}_{P S} M_{P S}+q_{P I} M_{P I}{ }^{\prime}-\left(\mathrm{q}_{P S} M_{P S}+\right.$ $\left.q_{P I} M_{P I}\right)$, where $M_{P I}{ }^{\prime}$ is the average completed fertility of those following a parity-independent approach from the second time point, and all other variables are estimates from the first time point. Thus, $\mathrm{q}_{P S} M_{P S}+q_{P I} M_{P I}{ }^{\prime}$ represents the hypothetical completed fertility at the second survey, if the only variable to change between surveys was the completed fertility of women following a parity-independent approach.

It is important to note that these two estimates of change-one based purely on changes in the proportion of parity-specific stopping, and one based purely on the change in mean fertility among those engaged in parity-independent strategies-will not necessarily sum to the total observed change, as there is an interaction between the changes in means and changes in proportions.

Finally, we assess the possibility that fertility declines that do not rely on parity-specific stopping are particularly common in sub-Saharan Africa (Moultrie et al. 2012). Specifically, we estimate the proportion of observed declines attributable: (1) solely to parity-specific stopping and (2) solely to declines in mean fertility among women following a parity-independent approach. We then compare the mean proportions for declines observed across five world regions (sub-Saharan Africa $(n=17)$, South Asia $(n=3)$, North Africa, Middle East and Central 
Asia; $n=7)$, Latin America and Caribbean $(n=7)$, Southeast Asia and Pacific $(n=4))$ and in two eras in the U.S. historical samples in which declines were observed.

\section{Results}

Goodness of fit to empirical distribution. The model shows good fit to observed distributions, with only 4 of the 301 model distributions from the DHS samples and 2 of the 12 model distributions from the U.S. census samples significantly different from their respective empirical distributions (bootstrapped chi-square test, 100000 replicates, Holm-Bonferroni correction for multiple tests with 313 tests). Importantly, the pure gamma-poisson model commonly used to model fertility distributions (which assumes no parity specific stopping) is statistically different from $54.5 \%$ of the 301 empirical samples from the DHS and $96.4 \%$ of the 12 empirical U.S. census samples. These results suggest that our proposed model accurately describes the patterns of fertility well in nearly all samples, and provides a much better fit in many cases than the pure gamma-poisson model.

There was little systematic deviation of predicted from observed proportions at each final parity, with the magnitude of the mean difference between predicted and observed parity proportions less than 0.01 . In those rare situations where the predictions and observations were statistically significant ( $n=4$ in DHS, $n=2$ in U.S.), the model generally over-estimated the proportion at parities $5 \& 6$ and under-estimated the proportion at parities $8,9 \& 10$ for DHS datasets and underestimated parity 0 for the US Census datasets (magnitude of mean deviation $>0.01$ ). However, these deviations were never greater than 0.03 . 
It is not clear what causes the greater occurrence of small, significant deviations of predictions from observed distributions in the U.S. samples (2 of 12 compared to 4 of 301 in the DHS samples). One hypothesis is that limiting parities to 12 in the U.S. data provided less information for fitting the Gamma-Poisson component of the model. This might increase the uncertainty of estimates and thereby reduce fit in any specific estimation. A related hypothesis is that in situations where a larger portion of the population is estimated as parity-specific stopping, there may be less information to provide accurate estimates of the Gamma-Poisson component. Future work should examine how small deviations arise from these and other aspects of data availability and model estimation.

What proportion of each sample follows parity-specific stopping (parities 1 through 5)? The proportion of women estimated to have stopped at specific parities varies from $0.7 \%$ (Rwanda 2000 and Burkina Faso 2014) to 84\% (in Ukraine 2007 and Armenia 2016) and increases as completed fertility goes down in DHS datasets ( $r=-0.65$ in DHS, $p<0.001)$, but not U.S. census samples ( $r=-0.26$ in U.S. census samples, $p>0.10$ ) (see supplemental materials for estimates for each survey and census). Figure 2a shows the proportion of women in each DHS sample estimated to follow parity-specific stopping and its relationship to the sample's mean completed fertility.

Notably, there is substantial variation in completed fertility even among those populations having very low proportions of parity-specific stopping (Figure 2a). This suggests there is ample room for decline without a shift to parity-specific stopping. For example, 
samples from Cambodia, South Africa, Bangladesh, Jordan, Rwanda, and Niger have comparably low estimates for parity-specific stopping ( $<5 \%$ of population), and yet mean completed fertility ranges from less than 4.5 in some samples (Cambodia, Myanmar, Vietnam, South Africa, Bangladesh, Uzbekistan) to more than 8.0 in others (Jordan, Rwanda, and Niger). Low mean fertility little parity-specific stopping is especially characteristic of early U.S. cohorts, with U.S. white, non-Hispanic women from the 1940 census (45-49 y) having completed fertility of 2.96 with only $7.5 \%$ estimated to follow parity-specific stopping.

Conversely, there are samples with comparable overall completed fertility, but very different estimates for the proportion of the population following parity-specific stopping. For example, Turkey 2004 and South Africa 1998 have nearly the same completed fertility (4.0 and 4.2, resp.), but strikingly different estimates of the proportion following parity-specific stopping (44\% and $2 \%$, resp.).

Among those women following parity-specific stopping, there is a clear bias toward parity $0 \& 2$ in both the DHS and U.S. census samples (Figure 3). However, there are also nontrivial numbers stopping at parities one, three, and to a much lesser extent four. There is almost no excess of parity-specific stopping at five children, suggesting that the vast majority of parity-specific stopping is concentrated between 0 and 4 children. This suggests that the model is suitably flexible-permitting stopping at 0 to 5 -to detect those parities at which parity specific stopping is most heavily concentrated and to show what parities are unlikely to be a target for stopping ( 5 and to a lesser extent 4 children). 
What is the mean completed fertility of women following a parity-independent approach? The mean rate for women following a parity-independent approach ranged from 2.0 (Armenia 2016) to 8.9 (Jordan 1990). It was also negatively correlated with the proportion of parityspecific stoppers in DHS samples $(r=-0.54, p<0.001)$ but not US Census samples $(r=-0.32, p>$ 0.10). Figure $2 b$ shows the mean completed fertility of women following a parity-independent approach by the mean completed fertility for the entire sample. Given the low proportion of parity-specific stopping in many of the samples, the overall tight correlation is not surprising.

Associations of parity-specific stopping with micro-level data. Estimates of parity-specific stopping were strongly correlated with an established population-level measure of parityspecific limitation - the steepness of reductions in parity progression ratios at low parities (reduction in parity progression from $2^{\text {st }}$ to $3^{\text {nd }}$ birth compared to $1^{\text {st }}$ to $2^{\text {nd }}$ birth, $r=0.85$; from $3^{\text {rd }}$ to $4^{\text {th }}$ birth compared to $2^{\text {nd }}$ to $\left.3 r d, r=0.54, p s<0.001, n=267\right)$. Estimates of parity-specific stopping were also strongly correlated with the magnitude of deviations from a Poisson assumption of equal median inter-birth intervals ( $r=0.60, p<0.001, n=267)$.

How do these results change with alternative samples and measures? Several checks with alternative samples (e.g. ever married women 45-49 y) and measures (living children vs. liveborn children) in the DHS surveys suggests that the model produces robust results. Specifically, key estimates for ever married DHS samples were strongly correlated with estimates from the full sample (parity-specific stopping $r=0.99$, rate for parity-independent 
strategies $r=0.99$, rate variance for parity-independent strategies $r=0.99$ ). As expected from the higher fertility of ever married populations, the average rate is higher among ever married women than among all women $(0.2$ child difference for populations at mean parity $=2,0.1$ child difference at mean parity $=4$, and 0.05 child difference at mean parity $=6$ ). Moreover, the variance in rates among ever-married women is on average $3.8 \%$ lower indicating a more homogenous set of rates when compared to the full sample.

Key estimates for living children are also strongly correlated with the original estimates for all liveborn children (parity-specific stopping $r=0.93$, rate for parity-independent strategies $r=0.92$, rate variance for parity-independent strategies $r=0.75)$. The relationship between parity-specific estimates based on the two measures is near equality (slope $=1.01$, intercept $=$ 0.02). As expected from the lower counts of living children, the rates among women following parity-independent approaches are lower when considering only living children among high parity populations ( 0.4 child difference for populations with mean parity $=4$, and 0.9 child difference when mean parity $=6)$. Notably, the variance in rates is also substantially lower when the model is applied to living children, with a 59\% reduction in rate variance when considering living versus liveborn children. This indicates that a large portion of heterogeneity in completed fertility among women following a parity-independent approach is due to differences in the number of non-surviving children (Ben-Porath 1976; Hossain et al. 2007).

How are parity-specific stopping \& parity-independent strategies associated with education and household wealth? The estimated proportion of individuals following parity-specific stopping is 
associated with other factors normally coinciding with declining fertility-sample's mean household wealth $(r=0.49, p<0.001)$ and proportion of women with at least primary education $(r=0.44, p<0.001)$ or secondary education $(r=0.61, p<0.001)$. There is also a strong negative correlation between the mean parity-independent lifetime rate with mean household wealth $(r=-0.58, p<0.001)$ and proportion women with at least primary education $(r=-0.63, p<0.001)$ or at least secondary education $(r=-0.72, p<0.001)$.

How much of the fertility decline is attributable to declining parity-independent lifetime rates versus increasing proportions of parity-specific stopping. Figure 4 illustrates the long-term change in estimates for: (1) proportion of women stopping at specific parities and (2) those following a parity-independent approach across U.S. Census birth cohorts. Mean completed fertility exhibits an initial sharp decline, and then a reversal and return associated with the baby boom. The initial fertility decline between the 1880 and 1910 cohorts from 3.2 to 2.3 children is accompanied by an increase in parity-specific stopping from approx. $5 \%$ to $25 \%$. However, if the only thing to change during that decline were parity-specific stopping, we would have expected a decline of only 0.1 children instead of the observed 0.9 children reduction. Meanwhile, if the only thing to change during that time was declining fertility among women following a parity-independent approach, we would expect a decline of 0.8 children, which is much closer to the observed decline. A similar result obtains when we examine the second decline between cohorts born in the 1930s and 1940s from 3.1 to 2.4 children. In this case, a 0.7 reduction is attributable to parity-independent strategies, while only 0.2 of the reduction is attributable to parity-specific stopping. 
We observe similar results when considering the 39 DHS countries which exhibited fertility declines of more than 0.5 children between the first and last DHS survey (Figure 5). In most cases, the expected contribution to the decline from parity-independent strategies alone is much greater than the expected contribution from parity-specific stopping alone. Moreover, the pattern is quite consistent across all five world regions, suggesting that the majority of fertility declines (at least in the $20^{\text {th }}$ century) can be attributed to parity-independent strategies (through spacing, postponement, later births or stopping for other reasons) rather than a switch to parity-specific stopping (Moultrie et al. 2012).

\section{Discussion}

Our findings suggest that an increase in stopping at specific parities accompanies many fertility declines, but that such parity-specific stopping is not necessarily responsible for much overall reduction. Rather, in both the U.S. and low- and middle-income country samples, we estimate that the bulk of declining fertility appears to be due to a decline in births among women following parity-independent strategies. Moreover, this parity-independent approach to fertility decline appears to be quite widespread, and is not unique to a given world region. This suggests that observations in sub-Saharan Africa of strategic birth spacing and postponement as well as delayed first birth and parity-independent stopping are more globally widespread (Bledsoe and Banja 2002; Johnson-Hanks 2007; Moultrie et al. 2012; Van Lith et al. 2013), and 
may even account for historical $20^{\text {th }}$ century declines in higher income countries, such as the U.S.

These findings raise the possibility that parity-specific stopping is a byproduct of the same societal changes leading to declining fertility, but that it does not necessarily play a direct causal role in fertility declines. One scenario consistent with these estimates is that increasing opportunities through education make a large portion of the population reduce fertility by spacing and postponing their timing of births. Meanwhile, increasing education also changes thinking among a subset of women, so that they begin to engage in parity-specific stopping. Although increases in parity-specific stopping coincide with overall declining fertility, under this scenario parity-specific stopping would in fact be a lagging indicator of fertility decline.

The model also identifies potentially significant within-sample heterogeneity in the proportion following a parity-independent approach. This suggests that characterizing entire societies or populations as having one strategy or another (e.g. "controlled fertility populations", "natural fertility population", and "societies" that focus on child numbers or manage reproduction) masks potentially important variation in strategies within populations (Johnson-Hanks 2008; Stulp and Barrett 2016; Stulp et al. 2016). Focusing on changes in withinsample heterogeneity might also shed light on observed shifts from over- to under-dispersion in completed fertility relative to a Poisson distribution as samples move from high to low fertility (van Daalen and Caswell 2015; Hruschka and Burger 2016). Specifically, we show that high and middle fertility populations are characterized by most women following a parity-independent approach which creates distributions that are more likely to be overdispersed relative to a Poisson distribution. By contrast, in samples with lower fertility, a larger portion follow parity- 
specific stopping at low fertilities which will create distributions that are under-dispersed relative to a Poisson.

Estimates of heterogeneity in parity-specific stopping also raise new important questions. Our findings suggest that a much larger proportion of the population follows parityspecific stopping in low fertility settings compared to high fertility settings. Moreover, the samples with high levels of parity-specific stopping exhibit striking variation among themselves, with modes ranging between one (Ukraine 2007), two (most countries), and three (Armenia 2005). This in turn raises important questions about what causes individuals to focus on specific sets of targets once they begin engaging in parity-specific stopping. Are these due to the influence of culturally arbitrary social norms or rather ecological constraints that lead to different optima (Melkersson and Rooth 2000; Silva and Covas 2000; Winterhalder and Leslie 2002; Sobotka and Beaujouan 2014)?

The current model is intended as a first approximation to population variation in strategies, but also provides a platform for further refinements. Parity-independent strategies comprise a range of behaviours including delayed age at first birth (Allal et al. 2004), spacing of births conditioned on the age of previous children, differing likelihood of replacement for prior infant deaths, and postponement for other reasons (Timæus and Moultrie 2008). This raises important questions about the distal causes of variation in these different proximate mechanisms, and whether these arise from greater availability of contraceptive technology or education leading to age at first birth or later age at marriage, to name a few possibilities. The modelling framework we outline here provides an avenue for answering these questions with the possibility of adding fixed effect predictors (e.g. maternal education) of the key model 
parameters. The current analyses also focused only on completed fertility at the end of women's reproductive careers. However, it is likely that women's strategies vary over time as they enter new life stages and situations. Future work examining the progression of agespecific fertility distributions over the life course may permit a finer-grained analysis of how strategies change over the life course. Finally, future work with the model should also examine how sensitive estimates and fit are to different kinds of data. For example, data limitations from the U.S. required us to limit parities to a maximum of 12 . This may provide less information for fitting the Gamma-Poisson component of the model, and thus increase the uncertainty of estimates and reduce fit in any specific estimation. It may also account for the fact that in 2 of 12 U.S. samples, but only 3 of DHS samples, was there a significant difference between the model prediction and the observed distribution.

As an approximation based on coarse-grained population data, the model has a number of limitations. Most notably, it can be difficult to infer the underlying criteria people use to make decisions from the patterns of behaviour observed in populations. However, we suggest that this is one approach which can be used alongside other methods in efforts to triangulate the fertility decision-making process. This is bolstered by the associations of our estimates of parity-specific stopping with other established measures of parity-based limitation and deviations from a Poisson process derived from micro-level birth records. At a minimum, the model provides a novel set of statistics on fertility distributions that researchers can begin to include in an existing toolkit for characterizing population variation and change in fertility. Acknowledging these limitations, a key advantage of the method presented here is that it is relatively simple and has minimal data requirements-requiring only synchronic data on 
completed fertility-compared to existing methods for estimating stopping and spacing. Thus, it opens opportunities for comparing the existence of parity-specific stopping and parityindependent strategies in a wide range of existing contemporary and historical datasets as long as they contain accurate information on the distribution of completed fertility. 


\section{References}

Allal, N., R. Sear, A. Prentice, and R. Mace. 2004. "An evolutionary model of stature, age at first birth and reproductive success in Gambian women." Proceedings of the Royal Society of London B: Biological Sciences 271(1538):465-470.

Anderton, D.L.and L.L. Bean. 1985. "Birth spacing and fertility limitation: A behavioral analysis of a nineteenth century frontier population." Demography 22(2):169-183.

Arnold, F. 1990. "Assessment of quality of birth history data in Demographic and Health Surveys." Pp. 81-111 in An assessment of DHS-I data quality. Columbia, Maryland: Institute for Resource Development / Macro Systems, Inc.

Ben-Porath, Y. 1976. "Fertility response to child mortality: micro data from Israel." Journal of Political Economy 84(4, Part 2):S163-S178.

Bledsoe, C., F. Banja, and A.G. Hill. 1998. "Reproductive mishaps and Western contraception: An African challenge to fertility theory." Population and Development Review 24(1):15-57.

Bledsoe, C.H.and F. Banja. 2002. Contingent lives: Fertility, time, and aging in West Africa. Chicago, USA: University of Chicago Press.

Bongaarts, J.and R.E. Potter. 2013. Fertility, biology, and behavior: An analysis of the proximate determinants. New York, USA: Academic Press.

Brass, W. 1958. "The distribution of births in human populations in rural Taiwan." Population Studies 12(1):51-72.

Brass, W., F. Juarez, and A. Scott. 1997. "An analysis of parity-dependent fertility falls in tropical Africa." Pp. 80-93 in The Continuing Demographic Transition, edited by G.W. Jones, R.M. Douglas, J.C. Caldwell, and R.M. D'Souza. Oxford, UK: Oxford University Press.

Casterline, J.B.and C. Odden. 2016a. "Exceptional or global? Evidence for postponement in the developing world." Presented at Annual Meeting of the Population Association of America, Washington, DC, March.

-. 2016b. "Trends in Inter-Birth Intervals in Developing Countries 1965-2014." Population and Development Review 42(2):173-194.

Cleland, J., S. Bernstein, A. Ezeh, A. Faundes, A. Glasier, and J. Innis. 2006. "Family planning: the unfinished agenda." The Lancet 368(9549):1810-1827. 
Coale, A.J. 1973. "The demographic transition reconsidered." Presented at Congres de l'IUSSP.

Coale, A.J.and T.J. Trussell. 1974. "Model fertility schedules: variations in the age structure of childbearing in human populations." Population Index 40(2):185-258.

Coombs, L.C. 1974. "The measurement of family size preferences and subsequent fertility." demography 11(4):587-611.

David, P.A., T.A. Mroz, W.C. Sanderson, K.W. Wachter, and D.R. Weir. 1988. "Cohort parity analysis: Statistical estimates of the extent of fertility control." Demography 25(2):163-188.

Eijkemans, M.J., F. Van Poppel, D.F. Habbema, K.R. Smith, H. Leridon, and E.R. Te Velde. 2014. "Too old to have children? Lessons from natural fertility populations." Human Reproduction 29(6):13041312.

Feng, W., J. Lee, and C. Campbell. 1995. "Marital fertility control among the Qing nobility: Implications for two types of preventive check." Population Studies 49(3):383-400.

Geweke, J. 1991. Evaluating the accuracy of sampling-based approaches to the calculation of posterior moments: Federal Reserve Bank of Minneapolis, Research Department Minneapolis, MN, USA.

Hayford, S.R.and V. Agadjanian. 2011. "Uncertain future, non-numeric preferences, and the fertility transition: A case study of rural Mozambique." African Population Studies 25(2):419.

Henry, L. 1961. "Natural Fertility--Observation, Theory, Results." Population 16(4):625-636.

Hionidou, V. 1998. "The adoption of fertility control on Mykonos, 1879-1959: stopping, spacing or both?" Population Studies 52(1):67-83.

Hossain, M.B., J.F. Phillips, and T.K. LeGrand. 2007. "The impact of childhood mortality on fertility in six rural thanas of Bangladesh." demography 44(4):771-784.

Hruschka, D.J.and O. Burger. 2016. "How does variance in fertility change over the demographic transition?" Philosophical Transactions of the Royal Society B 371(1692):1-8.

Hruschka, D.J., D. Gerkey, and C. Hadley. 2015. "Estimating the absolute wealth of households." Bulletin of the World Health Organization 93(7):483-490. 
ICF International. 1991-2014. "Demographic and Health Surveys (various) [Datasets]." Calverton, Maryland: ICF International.

Johnson-Hanks, J. 2008. "Demographic transitions and modernity." Annual Review of Anthropology 37:301-315.

Johnson-Hanks, J. 2002. "On the limits of life stages in ethnography: toward a theory of vital conjunctures." American Anthropologist 104(3):865-880.

-. 2007. "Natural Intentions: Fertility Decline in the African Demographic and Health Surveys1." American Journal of Sociology 112(4):1008-1043.

Kingsley, D. 1963. "The Theory of Change and Response in Modern Demographic History." Population Index 29(4):345-366.

Knodel, J. 1977. "Family limitation and the fertility transition: Evidence from the age patterns of fertility in Europe and Asia." Population Studies 31(2):219-249.

-. 1979. "From natural fertility to family limitation: The onset of fertility transition in a sample of German villages." Demography 16(4):493-521.

-. 1983. "Natural fertility: age patterns levels and trends." Pp. 61-102 in Determinants of fertility in developing countries, edited by R.A. Bulatao and R.D. Lee. New York: Academic Press.

-. 1987. "Starting, stopping, and spacing during the early stages of fertility transition: The experience of German village populations in the 18th and 19th centuries." Demography 24(2):143-162.

Knodel, J.and E. Van de Walle. 1979. "Lessons from the past: Policy implications of historical fertility studies." Population and Development Review 5(2):217-245.

Mason, K.O. 1997. "Explaining fertility transitions." Demography 34(4):443-454.

Mattison, S., C. Moya, A. Reynolds, and M.C. Towner. 2018. "Evolutionary demography of age at last birth: integrating approaches from human behavioural ecology and cultural evolution." Philosophical Transactions of the Royal Society B 373(1743):20170060.

Melkersson, M.and D.-O. Rooth. 2000. "Modeling female fertility using inflated count data models." Journal of Population Economics 13(2):189-203. 
Miranda, A. 2010. "A double-hurdle count model for completed fertility data from the developing world." in NCRM Working Paper: Department of Quantitative Social Science, Institute of Education.

Moultrie, T.A., T.S. Sayi, and I.M. Timæus. 2012. "Birth intervals, postponement, and fertility decline in Africa: A new type of transition?" Population Studies 66(3):241-258.

Plummer, M., N. Best, K. Cowles, and K. Vines. 2006. "CODA: Convergence diagnosis and output analysis for MCMC." $R$ news 6(1):7-11.

Poston Jr, D.L.and S.L. McKibben. 2003. "Using zero-inflated count regression models to estimate the fertility of US women." Journal of Modern Applied Statistical Methods 2(2):10.

R Core Team. 2014. "R: A language and environment for statistical computing. R Foundation for Statistical Computing, Vienna, Austria. 2013." ISBN 3-900051-07-0.

Reher, D.S.and A. Sanz-Gimeno. 2007. "Rethinking historical reproductive change: Insights from longitudinal data for a Spanish town." Population and Development Review 33(4):703-727.

Ruggles, S., K. Genadek, R. Goeken, J. Grover, and M. Sobek. 2015. "Integrated Public use Microdata Series: Version 6.0 [Machine-readable database]." edited by U.o. Minnesota. Minneapolis.

Silva, J.S.and F. Covas. 2000. "A modified hurdle model for completed fertility." Journal of Population Economics 13(2):173-188.

Sobotka, T.and É. Beaujouan. 2014. "Two Is Best? The Persistence of a Two-Child Family Ideal in Europe." Population and Development Review 40(3):391-419.

Stulp, G.and L. Barrett. 2016. "Wealth, fertility and adaptive behaviour in industrial populations." Philosophical Transactions of the Royal Society B 371(1692):1-11.

Stulp, G., R. Sear, M. Mills, and L. Barrett. 2016. "The reproductive ecology of industrial societies: the association between wealth and fertility." Human Nature 27(4):445-470.

Szreter, S.and E. Garrett. 2000. "Reproduction, compositional demography, and economic growth: Family planning in England long before the fertility decline." Population and Development Review 26(1):45-80.

Timæus, I.M.and T.A. Moultrie. 2008. "On postponement and birth intervals." Population and Development Review 34(3):483-510. 
- . 2013. "Distinguishing the impact of postponement, spacing and stopping on birth intervals: Evidence from a model with heterogeneous fecundity." Journal of Biosocial Science 45(03):311-330.

Towner, M.C., I. Nenko, and S.E. Walton. 2016. "Why do women stop reproducing before menopause? A life-history approach to age at last birth." Philosophical Transactions of the Royal Society B 371(1692):20150147.

Van Bavel, J. 2004a. "Deliberate birth spacing before the fertility transition in Europe: Evidence from nineteenth-century Belgium." Population Studies 58(1):95-107.

-. 2004b. "Detecting stopping and spacing behaviour in historical demography. A critical review of methods." Population 59(1):117-128.

Van Bavel, J.and J. Kok. 2010. "A mixed effects model of birth spacing for pre-transition populations: Evidence of deliberate fertility control from nineteenth century Netherlands." The History of the Family 15(2):125-138.

van Daalen, S.and H. Caswell. 2015. "Lifetime reproduction and the second demographic transition: Stochasticity and individual variation." Demographic Research 33:561-588.

Van de Walle, E. 1992. "Fertility transition, conscious choice, and numeracy." Demography 29(4):487502.

Van Lith, L.M., M. Yahner, and L. Bakamjian. 2013. "Women's growing desire to limit births in subSaharan Africa: meeting the challenge." Global Health: Science and Practice 1(1):97-107.

Westoff, C.F.and A. Bankole. 2000. "Trends in the demand for family limitation in developing countries." International Family Planning Perspectives:56-97.

Winkelmann, R. 1995. "Duration dependence and dispersion in count-data models." Journal of Business \& Economic Statistics 13(4):467-474.

Winterhalder, B.and P. Leslie. 2002. "Risk-sensitive fertility: the variance compensation hypothesis." Evolution and Human Behavior 23(1):59-82.

Wood, J.W. 1994. Dynamics of human reproduction: biology, biometry, demography. New York, USA: Transaction Publishers. 


\section{Figure Legends}

Figure 1. Empirical completed fertility distributions (solid lines) compared with gammapoisson portion of best fitting model distributions (dotted lines) (women 45-49). 1 a. Bangladesh 1996 DHS vs. pure gamma-poisson ( $n=649), 1$ b Kazakhstan 1995 DHS vs. pure gamma-poisson ( $n=370$ ), 1c Kazakhstan 1995 DHS vs. gamma-poisson permitting parityspecific stopping at 0 to 5 children $(n=370), 1 d$ Ukraine 2007 DHS vs. gamma-poisson permitting parity-specific stopping at 0 to 5 children $(n=1082)$.

Figure 2. The relationship between sample mean completed fertility and: (a) proportion following parity-specific stopping at 1 to 5 children and (b) mean completed fertility among the complementary set following a parity-independent approach. Black dots = US samples, Hollow dots $=$ DHS samples .

Figure 3. Targets of parity-specific stopping. Among those who are parity-specific stoppers, the proportion targeting parities 0 through 5 in US Census and DHS samples. Error bar are $95 \% \mathrm{Cl}$.

Figure 4. Historical changes in U.S. fertility. Change in: (1) mean completed fertility, (2) estimated proportion following parity-specific stopping and (3) mean rate among those following parity-independent approach (12 cohorts of U.S. ever married, white non-Hispanic women, 1940-1990 Censuses, 45-49 and 50-54 y cohorts, point estimates and 95\% posterior bands)

Figure 5. Estimated contributions of parity-specific stopping and parity-independent strategies to fertility declines by world region. Includes countries with at least 0.5 child reduction over DHS surveys, and 2 declines in U.S. (1888 to 1908 cohorts \& 1933 to 1943 cohorts). (Mean and $95 \% \mathrm{Cl}$ of country estimates. Sample size for each region in parentheses). 

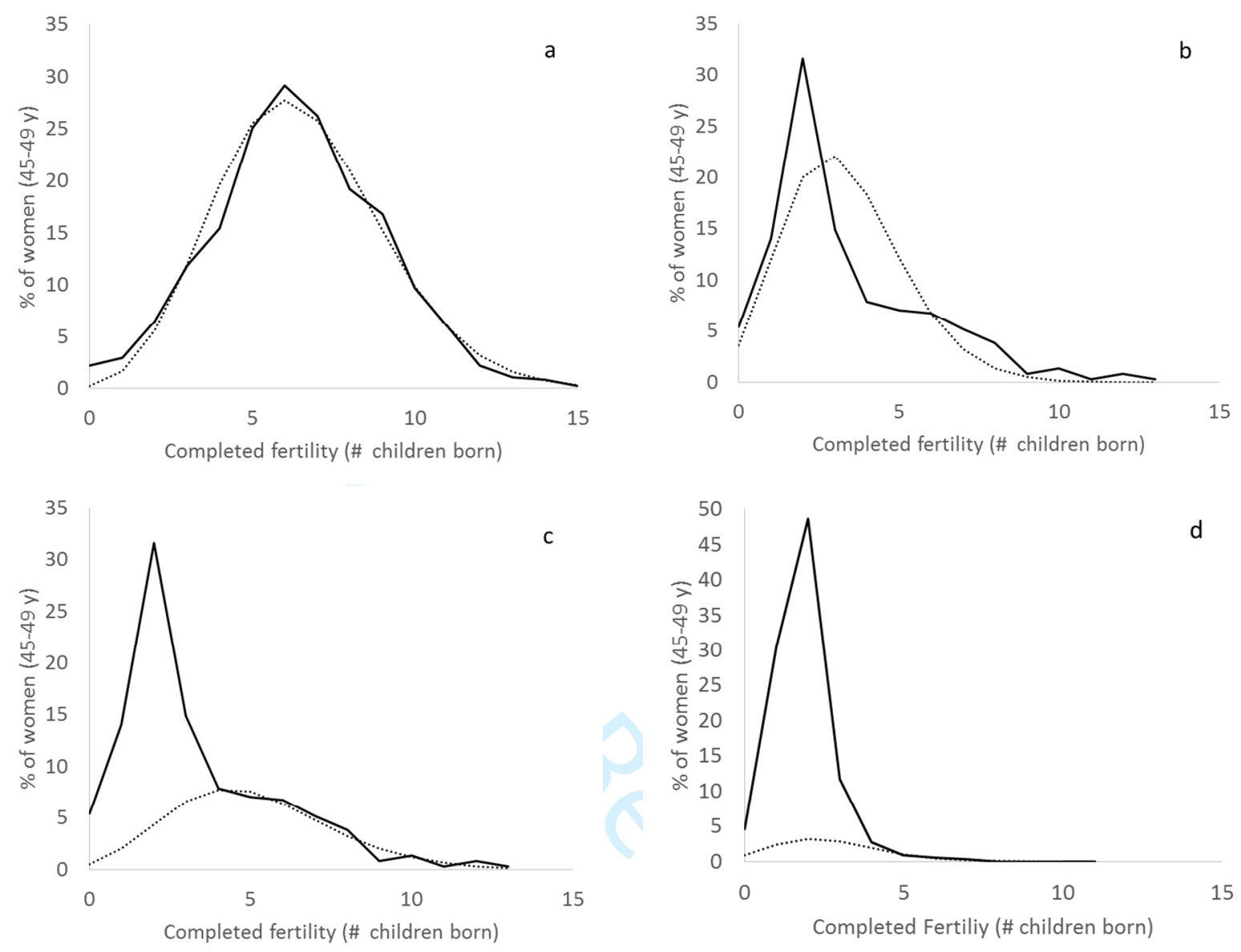

Figure 1. Empirical completed fertility distributions (solid lines) compared with gammapoisson portion of best fitting model distributions (dotted lines) (women 45-49). 1a. Bangladesh 1996 DHS vs. pure gamma-poisson $(n=649), 1 b$ Kazakhstan 1995 DHS vs. pure gamma-poisson ( $n=370)$, 1c Kazakhstan 1995 DHS vs. gamma-poisson permitting parityspecific stopping at 0 to 5 children $(n=370), 1 d$ Ukraine 2007 DHS vs. gamma-poisson permitting parity-specific stopping at 0 to 5 children $(n=1082)$. 

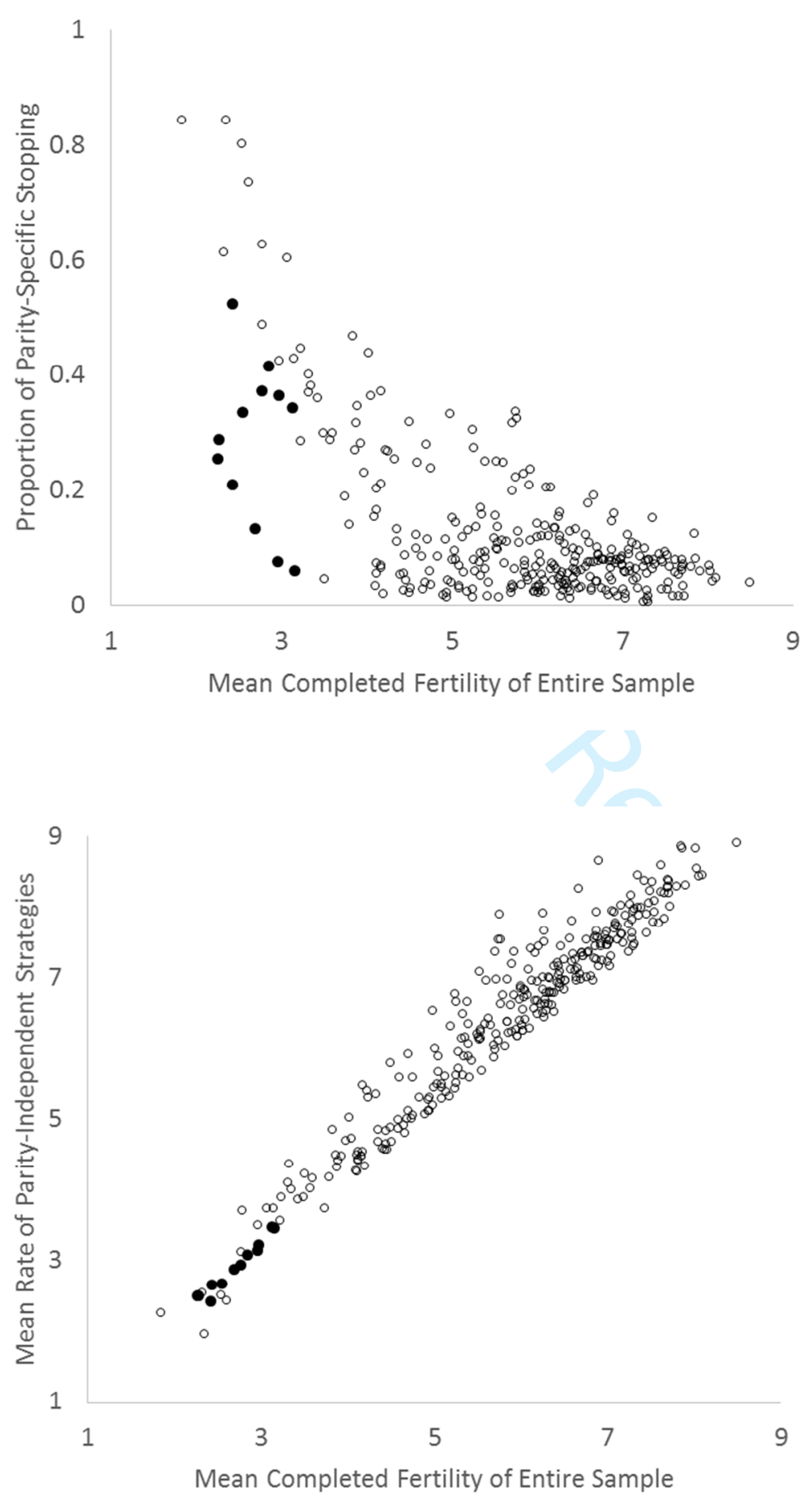

Figure 2. The relationship between sample mean completed fertility and: (a) proportion following parity-specific stopping at 1 to 5 children and (b) mean completed fertility among the complementary set following a parity-independent approach. Black dots = US samples, Hollow dots $=$ DHS samples. 


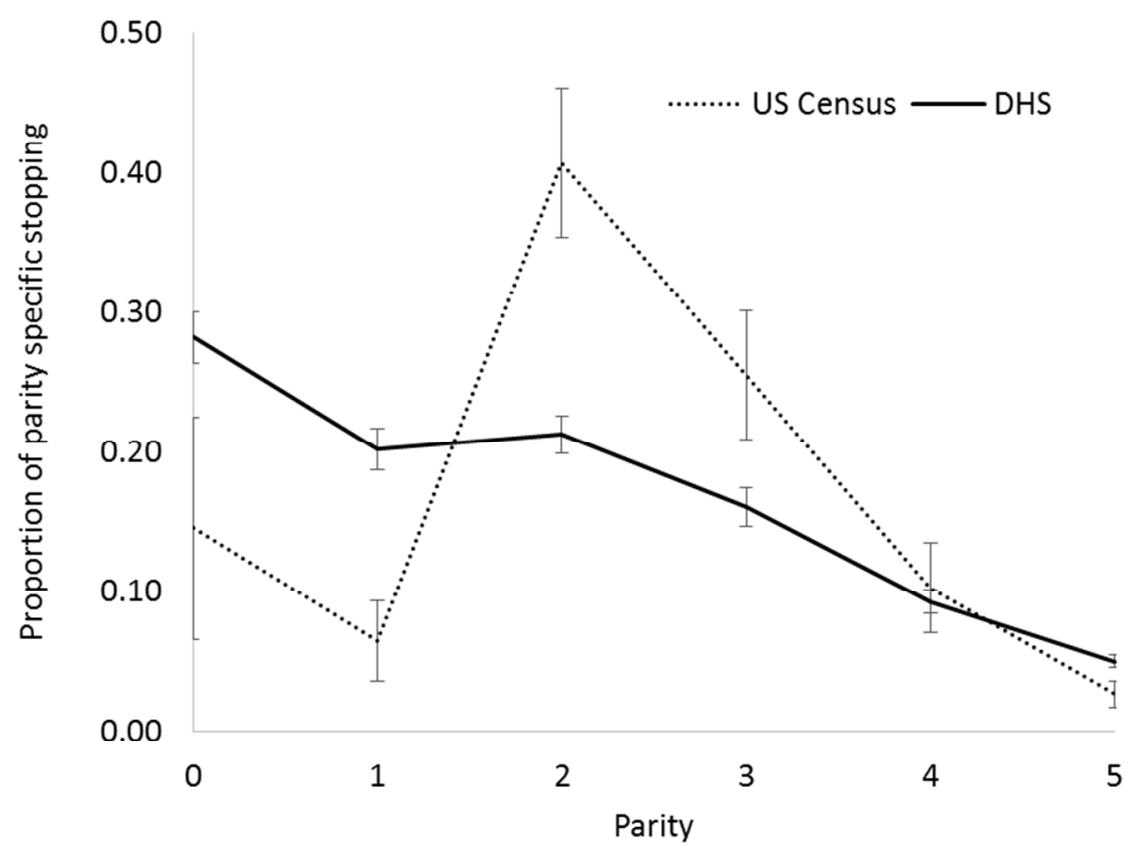

Figure 3. Targets of parity-specific stopping. Among those who are parity-specific stoppers, the proportion targeting parities 0 through 5 in US Census and DHS samples. Error bar are $95 \% \mathrm{Cl}$. 

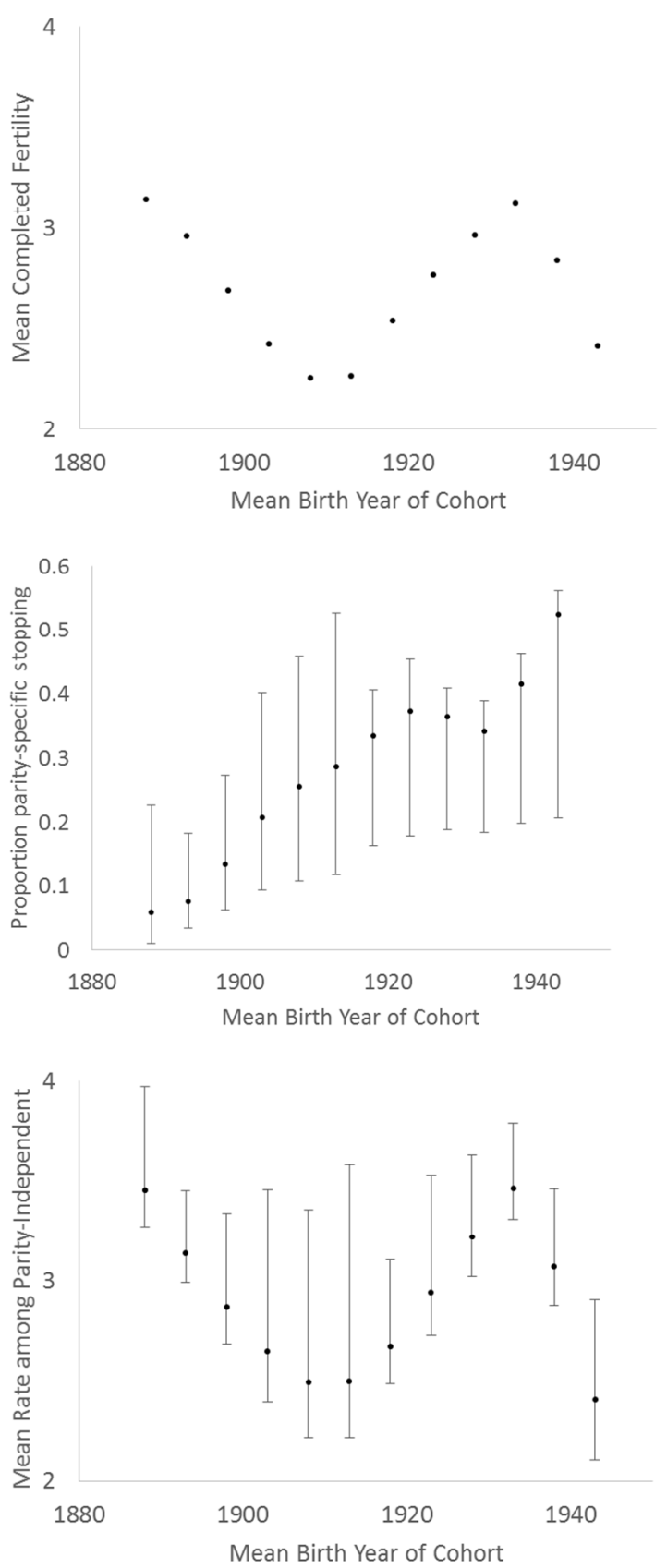

Figure 4. Historical changes in U.S. fertility. Change in: (1) mean completed fertility, (2) estimated proportion following parity-specific stopping and (3) mean rate among those following parity-independent approach (12 cohorts of U.S. ever married, white non-hispanic women, $1940-1990$ Censuses, $45-49$ and 50-54 y cohorts, point estimates and $95 \%$ posterior bands) 


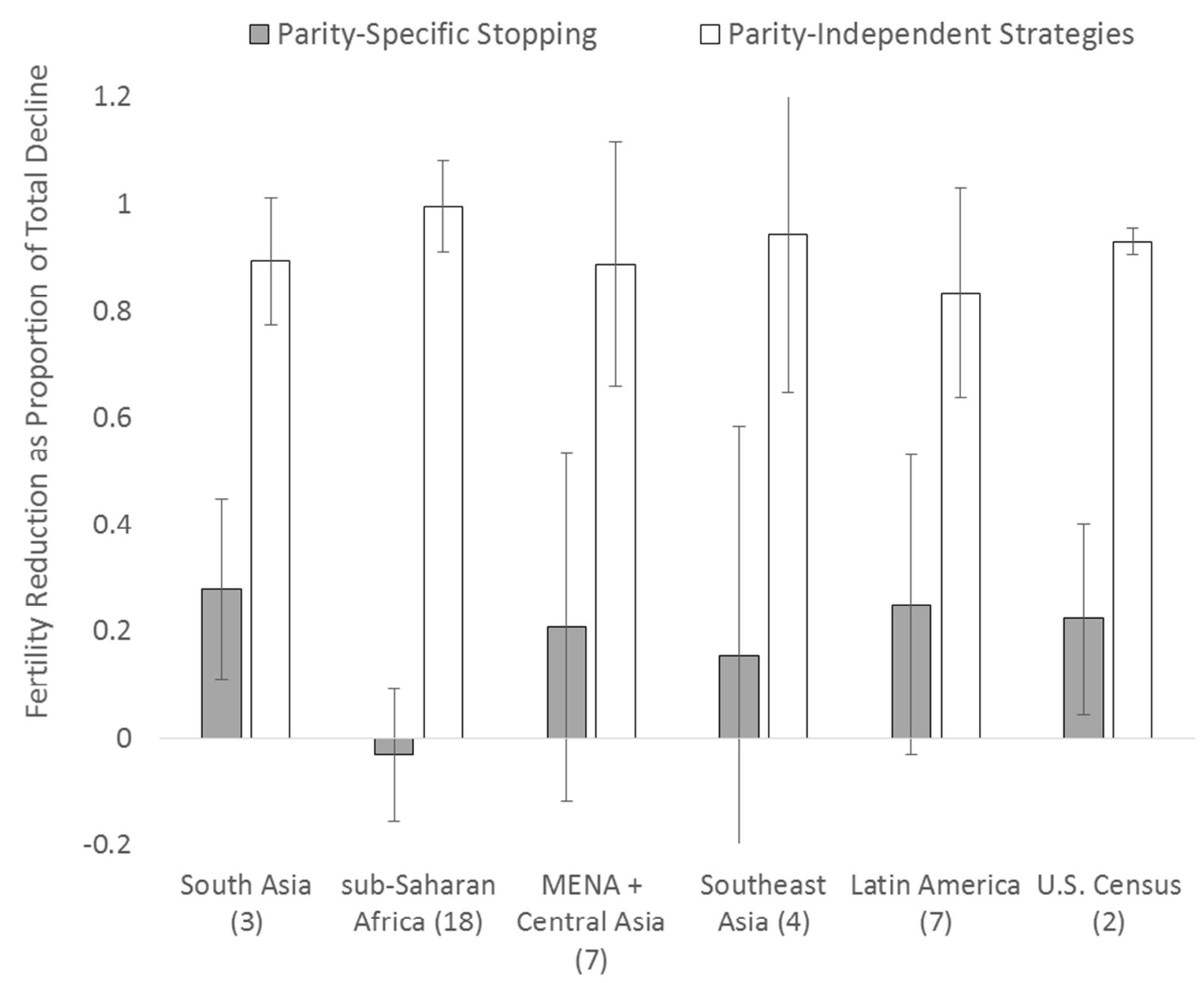

Figure 5. Estimated contributions of parity-specific stopping and parity-independent strategies to fertility declines by world region. Includes countries with at least 0.5 child reduction over DHS surveys, and 2 declines in U.S. (1888 to 1908 cohorts \& 1933 to 1943 cohorts). (Mean and $95 \% \mathrm{Cl}$ of country estimates. Sample size for each region in parentheses). MENA = Middle East and North Africa. 
Supplemental Materials.

Figure S.1. Distribution across DHS and samples $(n=301)$ of proportion engaged in parity-specific stopping (at 1 to 5).

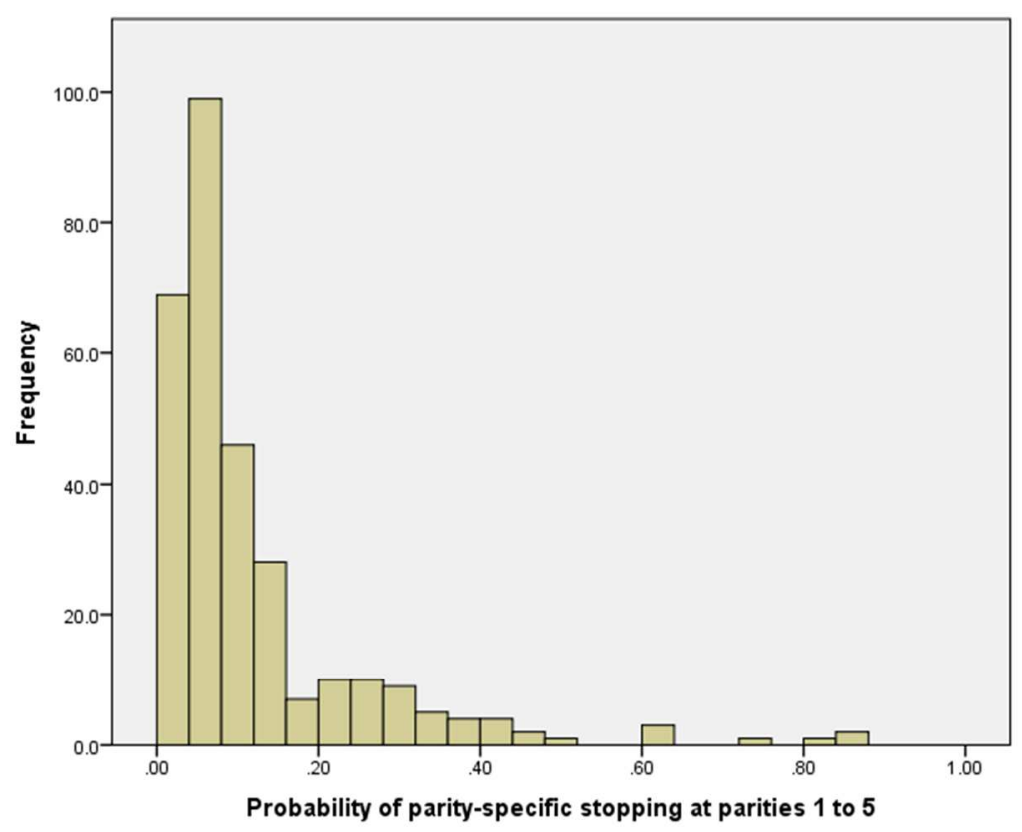


Countries associated with DHS 2-letter codes. $A F=$ Afghanistan, $A L=$ Albania, $A M=$ Armenia, $\mathrm{AO}=$ Angola, $\mathrm{AZ}=$ Azerbaijan, $\mathrm{BD}=$ Bangladesh, $\mathrm{BF}=$ Burkina Faso, $\mathrm{BJ}=$ Benin, $\mathrm{BO}=$ Bolivia, $\mathrm{BR}=$ Brazil, $\mathrm{BT}=$ Botswana, $\mathrm{BU}=$ Burundi, $\mathrm{CD}=\mathrm{DR}$ of Congo, $\mathrm{CF}=$ Central African Republic, $\mathrm{CG}=$ Congo, $\mathrm{Cl}=$ Cote D'Ivoire, $\mathrm{CM}=$ Cameroon, $\mathrm{CO}=$ Colombia, $\mathrm{DR}=$ Dominican Republic, $\mathrm{EC}=$ Ecuador, EG = Egypt, ES = El Salvador, ET = Ethiopia, GA = Gabon, GH = Ghana, GM = Gambia, $\mathrm{GN}=$ Guinea, $\mathrm{GU}=$ Guatemala, $\mathrm{HN}=$ Honduras, $\mathrm{HT}=$ Haiti, $\mathrm{IA}=$ India, ID = Indonesia, $\mathrm{JO}=$ Jordan, $\mathrm{KE}=$ Kenya, $\mathrm{KH}=$ Cambodia, $\mathrm{KK}=$ Kazakhstan, $\mathrm{KM}=$ Comoros, $\mathrm{KY}=$ Kyrgyzstan, $\mathrm{LB}=$ Liberia, $\mathrm{LK}=$ Sri Lanka, $\mathrm{LS}=$ Lesotho, $\mathrm{MA}=$ Morocco, $\mathrm{MD}=$ Madagascar, $\mathrm{ML}=$ Mali, $\mathrm{MM}=$ Myanmar, $\mathrm{MR}=$ Mauritania, $\mathrm{MV}=$ Maldives, $\mathrm{MW}=$ Malawi, $\mathrm{MZ}=$ Mozambique, $\mathrm{NC}=$ Nicaragua, $\mathrm{NG}=$ Nigeria, $\mathrm{NI}=$ Niger, $\mathrm{NM}=$ Namibia, $\mathrm{NP}=$ Nepal, $\mathrm{PE}=$ Peru, $\mathrm{PH}=$ Philippines, $\mathrm{PK}=$ Pakistan, $\mathrm{RW}=\mathrm{R}$ wanda, $\mathrm{SD}=$ Sudan, $\mathrm{SL}=$ Sierra Leone, $\mathrm{SN}=$ Senegal, $\mathrm{ST}=$ Sao Tome \& Principe, $\mathrm{SZ}=$ Swaziland, TD = Chad, TG = Togo, TR = Turkey, TT = Trinidad \& Tobago, TZ = Tanzania, UA = Ukraine, UG = Uganda, US = United States, UZ = Uzbekistan, VN = Vietnam, YE = Yemen, ZA = South Africa, ZM = Zambia, ZW = Zimbabwe

Table S.1. Observed and expected fertility declines from parity-specific stopping alone and parity-independent strategies alone $(C A=$ Central Asia, $L A C=$ Latin America and Caribbean, MENA = North Africa \& Middle East, SSA = sub-saharan Africa, SA = South Asia, SEA = Southeast Asia).

\begin{tabular}{|c|c|c|c|c|c|c|c|}
\hline & & & & & 8 & Estimated reduction as & ortion of total decline \\
\hline Country & Start & $\begin{array}{c}\text { Regio } \\
\mathrm{n}\end{array}$ & Span (y) & $\begin{array}{c}\text { Start } \\
\text { Fertility }\end{array}$ & Change & $\begin{array}{c}\text { Parity-specific } \\
\text { Stopping alone } \\
\end{array}$ & $\begin{array}{l}\text { Parity-independent } \\
\text { strategies alone }\end{array}$ \\
\hline $\mathrm{AO}$ & 2006 & SSA & 9 & 7.01 & -1.16 & 0.35 & 0.7 \\
\hline $\mathrm{BD}$ & 1994 & SA & 20 & 6.83 & -2.73 & 0.17 & 0.96 \\
\hline BJ & 1996 & SSA & 16 & 7.53 & -2.19 & 0.24 & 0.83 \\
\hline $\mathrm{BO}$ & 1989 & LAC & 19 & 5.9 & -0.66 & 0.56 & 0.49 \\
\hline $\mathrm{BR}$ & 1991 & LAC & 5 & 6.03 & -1.81 & 0.51 & 0.65 \\
\hline $\mathrm{CO}$ & 1986 & LAC & 29 & 6.09 & -2.94 & 0.39 & 0.95 \\
\hline $\mathrm{DR}$ & 1986 & LAC & 27 & 7.35 & -2.27 & -0.2 & 1.08 \\
\hline EG & 1988 & $\begin{array}{c}\text { MEN } \\
\text { A }\end{array}$ & 26 & 6.19 & -2.15 & 0.45 & 0.82 \\
\hline ET & 2000 & SSA & 16 & 6.87 & -0.73 & 0.44 & 0.59 \\
\hline GA & 2000 & SSA & 12 & 6.21 & -0.5 & 0.29 & 0.75 \\
\hline $\mathrm{GH}$ & 1988 & SSA & 28 & 7.25 & -1.84 & -0.15 & 1.08 \\
\hline GN & 1999 & SSA & 13 & 6.88 & -0.52 & -0.21 & 1.17 \\
\hline GU & 1995 & LAC & 20 & 6.6 & -1.62 & 0.51 & 0.62 \\
\hline $\mathrm{HN}$ & 2006 & LAC & 6 & 5.84 & -0.8 & -0.38 & 1.22 \\
\hline IA & 1993 & SA & 22 & 4.93 & -1.36 & 0.45 & 0.77 \\
\hline ID & 1987 & SEA & 25 & 5.59 & -1.99 & 0.26 & 0.93 \\
\hline
\end{tabular}




\begin{tabular}{|c|c|c|c|c|c|c|c|}
\hline JO & 1990 & MEN & 22 & 8.5 & -2.78 & 0.11 & 0.92 \\
\hline KE & 1989 & SSA & 26 & 7.66 & -2.33 & -0.06 & 1.01 \\
\hline KH & 2000 & SEA & 14 & 5.62 & -1.5 & -0.22 & 1.14 \\
\hline KK & 1995 & CA & 4 & 3.32 & -0.54 & 0.47 & 0.73 \\
\hline KM & 1996 & SSA & 16 & 7.06 & -1.73 & 0.05 & 0.89 \\
\hline KY & 1997 & CA & 15 & 4.6 & -0.86 & -0.72 & 1.56 \\
\hline LS & 2004 & SSA & 10 & 5.17 & -1.07 & 0.04 & 0.96 \\
\hline MA & 1987 & MEN & 16 & 7.43 & -2.24 & 0.28 & 0.79 \\
\hline MD & 1992 & SSA & 24 & 6.9 & -1.62 & -0.72 & 1.36 \\
\hline MW & 1992 & SSA & 23 & 7.37 & -1.18 & -0.14 & 1.09 \\
\hline NM & 1992 & SSA & 21 & 6 & -1.84 & -0.2 & 1.09 \\
\hline NP & 1996 & SA & 20 & 6.01 & -1.85 & 0.22 & 0.94 \\
\hline PE & 1986 & LAC & 26 & 6.34 & -2.36 & 0.36 & 0.83 \\
\hline PH & 1993 & SEA & 20 & 5.39 & -1.27 & -0.15 & 1.18 \\
\hline RW & 1992 & SSA & 23 & 8.09 & -2.39 & 0.05 & 0.95 \\
\hline SN & 1986 & SSA & 30 & 7.27 & -1.01 & -0.22 & 1.16 \\
\hline TG & 1988 & SSA & 26 & 7.28 & -1.23 & 0.07 & 0.94 \\
\hline TR & 1993 & CA & 20 & 4.93 & -1.62 & 0.61 & 0.64 \\
\hline TZ & 1991 & SSA & 24 & 7.09 & -0.86 & -0.24 & 1.19 \\
\hline VN & 1997 & SEA & 8 & 4.46 & -1.23 & 0.73 & 0.52 \\
\hline YE & 1991 & MEN & 22 & 7.9 & -0.62 & 0.25 & 0.75 \\
\hline ZM & 1992 & SSA & 21 & 8.03 & -1.31 & 0.13 & 0.88 \\
\hline ZW & 1988 & SSA & 27 & 6.87 & -2.76 & 0.03 & \\
\hline
\end{tabular}

Table S.2. Sample descriptives and key estimates for global DHS and U.S. Census samples $(n=313)$. Survid can be used to identify individual figures in figure S.4 for U.S.

\begin{tabular}{|l|l|l|l|l|l|l|l|l|l|}
\hline & & & & & & \multicolumn{2}{l|}{$\begin{array}{l}\text { Parity-specific } \\
\text { stopping }\end{array}$} & \multicolumn{2}{l|}{$\begin{array}{l}\text { Expected completed } \\
\text { fertility }\end{array}$} \\
\hline survid & Country & $\begin{array}{l}\text { Survey } \\
\text { Year }\end{array}$ & $\begin{array}{l}\text { Birth } \\
\text { Cohort }\end{array}$ & $\begin{array}{l}\text { Complete } \\
\text { Fertility }\end{array}$ & $\begin{array}{l}\text { Sample } \\
\text { Size }\end{array}$ & Parity 0 & $\begin{array}{l}\text { Parity 1 } \\
\text { to 5 }\end{array}$ & $\begin{array}{l}\text { Parity- } \\
\text { independent }\end{array}$ & $\begin{array}{l}\text { Parity- } \\
\text { specific }\end{array}$ \\
\hline & AF & 2010 & 1963 & 7.18 & 2624 & 0.02 & 0.03 & 7.49 & 1.02 \\
\hline & AF & 2015 & 1968 & 7.28 & 3126 & 0.03 & 0.01 & 7.55 & 0.37 \\
\hline & AL & 2008 & 1961 & 3.07 & 1061 & 0.02 & 0.60 & 3.73 & 2.68 \\
\hline & AM & 2000 & 1953 & 2.77 & 806 & 0.07 & 0.63 & 3.12 & 2.64 \\
\hline & AM & 2005 & 1958 & 2.61 & 1000 & 0.03 & 0.74 & 2.42 & 2.71 \\
\hline & AM & 2010 & 1963 & 2.54 & 895 & 0.03 & 0.80 & 2.50 & 2.59 \\
\hline & AM & 2016 & 1969 & 2.35 & 714 & 0.02 & 0.84 & 1.95 & 2.46 \\
\hline & AO & 2006 & 1959 & 7.01 & 185 & 0.01 & 0.03 & 7.22 & 1.90 \\
\hline & AO & 2011 & 1964 & 6.10 & 397 & 0.01 & 0.02 & 6.28 & 1.98 \\
\hline
\end{tabular}




\begin{tabular}{|c|c|c|c|c|c|c|c|c|}
\hline $\mathrm{AO}$ & 2015 & 1968 & 5.85 & 888 & 0.04 & 0.07 & 6.37 & 1.27 \\
\hline$A Z$ & 2006 & 1959 & 2.97 & 1018 & 0.08 & 0.42 & 3.49 & 2.46 \\
\hline $\mathrm{BD}$ & 1994 & 1947 & 6.83 & 644 & 0.01 & 0.02 & 6.96 & 1.74 \\
\hline $\mathrm{BD}$ & 1996 & 1949 & 6.39 & 649 & 0.01 & 0.01 & 6.51 & 1.46 \\
\hline $\mathrm{BD}$ & 1999 & 1952 & 5.97 & 845 & 0.02 & 0.02 & 6.17 & 1.05 \\
\hline $\mathrm{BD}$ & 2004 & 1957 & 5.55 & 1075 & 0.01 & 0.01 & 5.67 & 1.64 \\
\hline $\mathrm{BD}$ & 2007 & 1960 & 4.89 & 1064 & 0.02 & 0.02 & 5.06 & 1.32 \\
\hline $\mathrm{BD}$ & 2011 & 1964 & 4.40 & 1848 & 0.01 & 0.05 & 4.57 & 2.30 \\
\hline $\mathrm{BD}$ & 2014 & 1967 & 4.09 & 1814 & 0.01 & 0.15 & 4.26 & 3.32 \\
\hline $\mathrm{BF}$ & 1993 & 1946 & 7.73 & 367 & 0.03 & 0.02 & 8.01 & 0.87 \\
\hline $\mathrm{BF}$ & 1999 & 1952 & 7.60 & 478 & 0.01 & 0.02 & 7.77 & 1.34 \\
\hline $\mathrm{BF}$ & 2003 & 1956 & 7.30 & 1077 & 0.01 & 0.02 & 7.46 & 1.20 \\
\hline $\mathrm{BF}$ & 2010 & 1963 & 7.03 & 1326 & 0.01 & 0.01 & 7.15 & 0.75 \\
\hline $\mathrm{BF}$ & 2014 & 1967 & 7.24 & 569 & 0.01 & 0.01 & 7.35 & 0.95 \\
\hline BJ & 1996 & 1949 & 7.53 & 460 & 0.01 & 0.03 & 7.78 & 1.11 \\
\hline BJ & 2001 & 1954 & 7.17 & 441 & 0.03 & 0.05 & 7.61 & 1.40 \\
\hline BJ & 2006 & 1959 & 6.81 & 1423 & 0.01 & 0.03 & 7.01 & 1.07 \\
\hline BJ & 2012 & 1965 & 5.34 & 1138 & 0.03 & 0.09 & 5.89 & 1.37 \\
\hline BO & 1989 & 1942 & 5.90 & 630 & 0.04 & 0.21 & 7.19 & 2.03 \\
\hline BO & 1994 & 1947 & 5.92 & 712 & 0.04 & 0.24 & 7.37 & 2.07 \\
\hline BO & 1998 & 1951 & 5.39 & 962 & 0.04 & 0.25 & 6.66 & 2.29 \\
\hline BO & 2003 & 1956 & 5.61 & 1481 & 0.04 & 0.25 & 6.95 & 2.21 \\
\hline $\mathrm{BO}$ & 2008 & 1961 & 5.24 & 1600 & 0.04 & 0.31 & 6.76 & 2.35 \\
\hline BR & 1991 & 1944 & 6.03 & 528 & 0.08 & 0.03 & 6.72 & 0.65 \\
\hline BR & 1996 & 1949 & 4.22 & 1147 & 0.07 & 0.27 & 5.39 & 2.14 \\
\hline BT & 2007 & 1960 & 4.65 & 400 & 0.00 & 0.09 & 4.91 & 2.43 \\
\hline $\mathrm{BU}$ & 1987 & 1940 & 7.12 & 277 & 0.02 & 0.04 & 7.54 & 0.85 \\
\hline BU & 2010 & 1963 & 6.94 & 691 & 0.03 & 0.02 & 7.24 & 0.81 \\
\hline BU & 2012 & 1965 & 6.64 & 340 & 0.03 & 0.03 & 7.00 & 0.93 \\
\hline CD & 2007 & 1960 & 6.63 & 685 & 0.03 & 0.07 & 7.25 & 1.46 \\
\hline$C D$ & 2013 & 1966 & 6.71 & 1323 & 0.03 & 0.09 & 7.34 & 1.57 \\
\hline CF & 1994 & 1947 & 5.74 & 424 & 0.09 & 0.22 & 7.54 & 1.64 \\
\hline CG & 2005 & 1958 & 5.85 & 421 & 0.03 & 0.08 & 6.36 & 1.15 \\
\hline CG & 2009 & 1962 & 5.74 & 537 & 0.02 & 0.06 & 6.10 & 1.40 \\
\hline CG & 2011 & 1964 & 5.85 & 861 & 0.02 & 0.06 & 6.21 & 1.54 \\
\hline $\mathrm{Cl}$ & 1994 & 1947 & 6.86 & 487 & 0.03 & 0.08 & 7.58 & 1.21 \\
\hline $\mathrm{Cl}$ & 1998 & 1951 & 6.45 & 161 & 0.03 & 0.08 & 7.08 & 1.70 \\
\hline $\mathrm{Cl}$ & 2005 & 1958 & 6.26 & 372 & 0.02 & 0.11 & 6.99 & 1.48 \\
\hline $\mathrm{Cl}$ & 2012 & 1965 & 6.39 & 707 & 0.02 & 0.13 & 7.16 & 1.89 \\
\hline $\mathrm{CM}$ & 1991 & 1944 & 6.25 & 218 & 0.10 & 0.15 & 7.91 & 1.18 \\
\hline $\mathrm{CM}$ & \begin{tabular}{|l|}
1998 \\
\end{tabular} & 1951 & 6.27 & 334 & 0.08 & 0.12 & 7.50 & 1.10 \\
\hline $\mathrm{CM}$ & 2004 & 1957 & 6.46 & 733 & 0.04 & 0.13 & 7.44 & 1.51 \\
\hline $\mathrm{CM}$ & 2011 & 1964 & 6.05 & 1187 & 0.03 & 0.12 & 6.81 & 1.65 \\
\hline
\end{tabular}




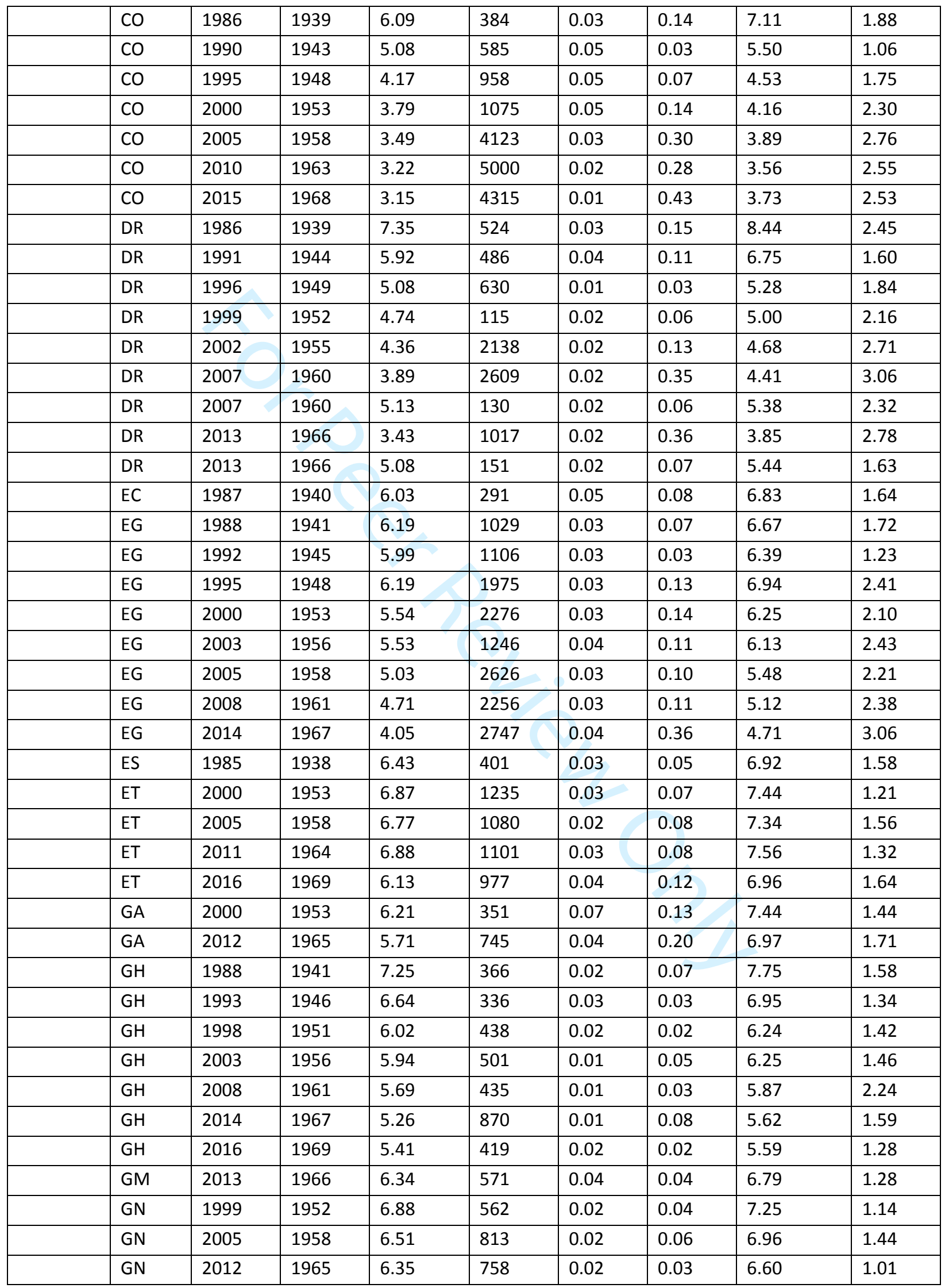




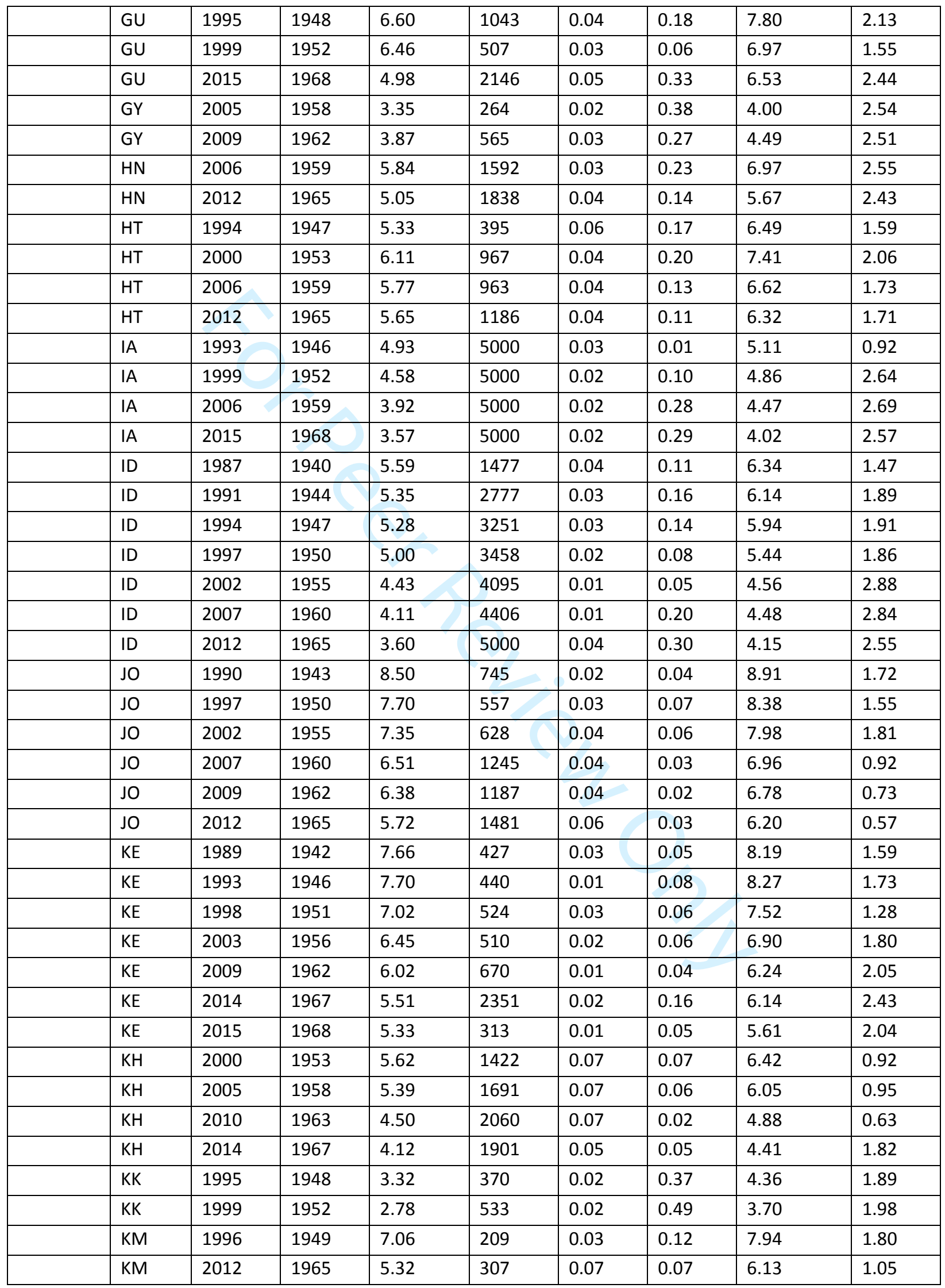




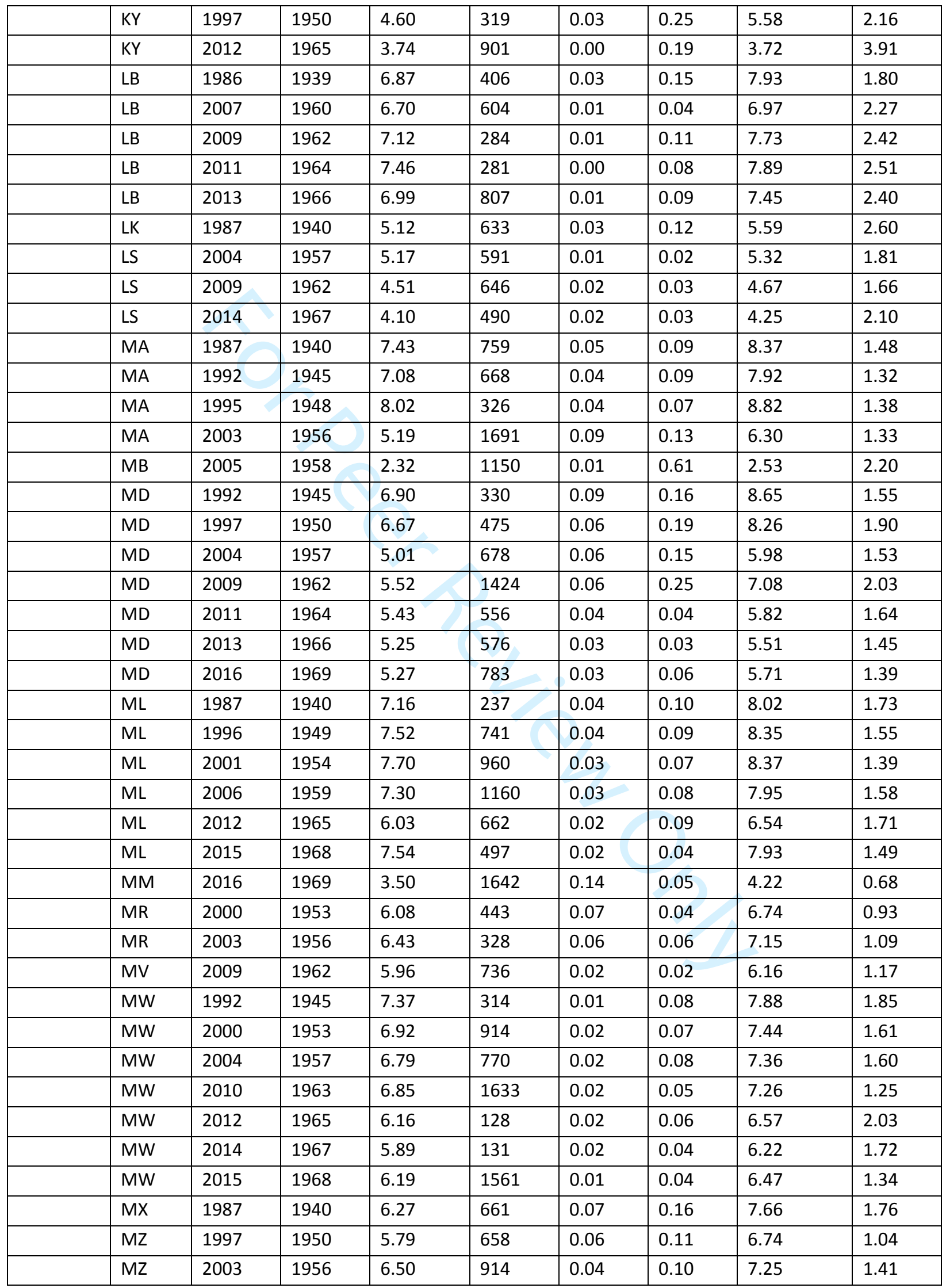




\begin{tabular}{|c|c|c|c|c|c|c|c|c|}
\hline $\mathrm{MZ}$ & 2009 & 1962 & 6.35 & 504 & 0.02 & 0.05 & 6.78 & 1.44 \\
\hline $\mathrm{MZ}$ & 2011 & 1964 & 5.50 & 1050 & 0.04 & 0.12 & 6.19 & 1.74 \\
\hline NC & 1998 & 1951 & 6.16 & 939 & 0.03 & 0.20 & 7.34 & 2.50 \\
\hline NC & 2001 & 1954 & 6.00 & 1028 & 0.03 & 0.12 & 6.84 & 2.31 \\
\hline NG & 1990 & 1943 & 6.57 & 602 & 0.05 & 0.12 & 7.55 & 1.67 \\
\hline NG & 2003 & 1956 & 6.99 & 618 & 0.03 & 0.08 & 7.64 & 1.82 \\
\hline NG & 2008 & 1961 & 6.99 & 2905 & 0.03 & 0.07 & 7.53 & 1.77 \\
\hline NG & 2010 & 1963 & 6.49 & 459 & 0.02 & 0.03 & 6.82 & 1.41 \\
\hline NG & 2013 & 1966 & 6.70 & 3555 & 0.03 & 0.10 & 7.35 & 2.32 \\
\hline NG & 2015 & 1968 & 6.30 & 467 & 0.04 & 0.04 & 6.78 & 1.47 \\
\hline $\mathrm{NI}$ & 1992 & 1945 & 7.85 & 373 & 0.03 & 0.12 & 8.85 & 2.00 \\
\hline $\mathrm{NI}$ & 1998 & 1951 & 7.62 & 499 & 0.05 & 0.08 & 8.58 & 1.08 \\
\hline $\mathrm{NI}$ & 2006 & 1959 & 7.70 & 675 & 0.03 & 0.06 & 8.29 & 1.31 \\
\hline $\mathrm{NI}$ & 2012 & 1965 & 8.05 & 749 & 0.02 & 0.04 & 8.43 & 1.51 \\
\hline NM & 1992 & 1945 & 6.00 & 349 & 0.03 & 0.14 & 6.87 & 1.75 \\
\hline NM & 2000 & 1953 & 5.39 & 447 & 0.01 & 0.08 & 5.89 & 2.06 \\
\hline NM & 2007 & 1960 & 4.76 & 713 & 0.03 & 0.03 & 5.05 & 1.28 \\
\hline NM & 2013 & 1966 & 4.16 & 754 & 0.03 & 0.07 & 4.46 & 1.95 \\
\hline NP & 1996 & 1949 & 6.01 & 826 & 0.03 & 0.03 & 6.32 & 1.03 \\
\hline NP & 2001 & 1954 & 5.81 & 850 & 0.02 & 0.04 & 6.03 & 2.06 \\
\hline NP & 2006 & 1959 & 5.24 & 867 & 0.03 & 0.01 & 5.43 & 0.91 \\
\hline NP & 2011 & 1964 & 4.58 & 950 & 0.03 & 0.12 & 4.99 & 2.56 \\
\hline NP & 2016 & 1969 & 4.16 & 1131 & 0.01 & 0.21 & 4.47 & 3.14 \\
\hline$P E$ & 1986 & 1939 & 6.34 & 396 & 0.03 & 0.04 & 6.78 & 1.52 \\
\hline $\mathrm{PE}$ & 1991 & 1944 & 5.70 & 1178 & 0.03 & 0.32 & 7.35 & 2.65 \\
\hline$P E$ & 1996 & 1949 & 5.76 & 2219 & 0.04 & 0.32 & 7.54 & 2.67 \\
\hline$P E$ & 2000 & 1953 & 5.26 & 2422 & 0.05 & 0.27 & 6.65 & 2.31 \\
\hline $\mathrm{PE}$ & 2004 & 1957 & 4.83 & 627 & 0.02 & 0.08 & 5.31 & 2.25 \\
\hline $\mathrm{PE}$ & 2006 & 1959 & 4.70 & 1282 & 0.04 & 0.28 & 5.91 & 2.11 \\
\hline$P E$ & 2008 & 1961 & 4.50 & 2427 & 0.04 & 0.32 & 5.79 & 2.25 \\
\hline$P E$ & 2009 & 1962 & 4.33 & 2516 & 0.04 & 0.25 & 5.34 & 2.06 \\
\hline $\mathrm{PE}$ & 2010 & 1963 & 4.24 & 2464 & 0.05 & 0.27 & 5.29 & 2.10 \\
\hline$P E$ & 2011 & 1964 & 4.17 & 2460 & 0.04 & 0.37 & 5.47 & 2.43 \\
\hline $\mathrm{PE}$ & 2012 & 1965 & 3.97 & 2611 & 0.04 & 0.23 & 4.68 & 2.20 \\
\hline $\mathrm{PH}$ & 1993 & 1946 & 5.39 & 1144 & 0.08 & 0.09 & 6.33 & 1.65 \\
\hline $\mathrm{PH}$ & 1998 & 1951 & 5.04 & 1215 & 0.07 & 0.08 & 5.89 & 1.21 \\
\hline $\mathrm{PH}$ & 2003 & 1956 & 4.69 & 1343 & 0.04 & 0.04 & 5.00 & 1.52 \\
\hline $\mathrm{PH}$ & 2008 & 1961 & 4.35 & 1445 & 0.05 & 0.11 & 4.85 & 1.93 \\
\hline $\mathrm{PH}$ & 2013 & 1966 & 4.12 & 1818 & 0.05 & 0.07 & 4.53 & 1.59 \\
\hline PK & 1991 & 1944 & 6.62 & 620 & 0.03 & 0.05 & 7.10 & 1.17 \\
\hline PK & 2006 & 1959 & 6.45 & 1228 & 0.03 & 0.04 & 6.85 & 1.03 \\
\hline PK & 2012 & 1965 & 6.17 & 1674 & 0.03 & 0.07 & 6.67 & 1.90 \\
\hline PY & 1990 & 1943 & 5.75 & 461 & 0.05 & 0.34 & 7.90 & 2.26 \\
\hline
\end{tabular}




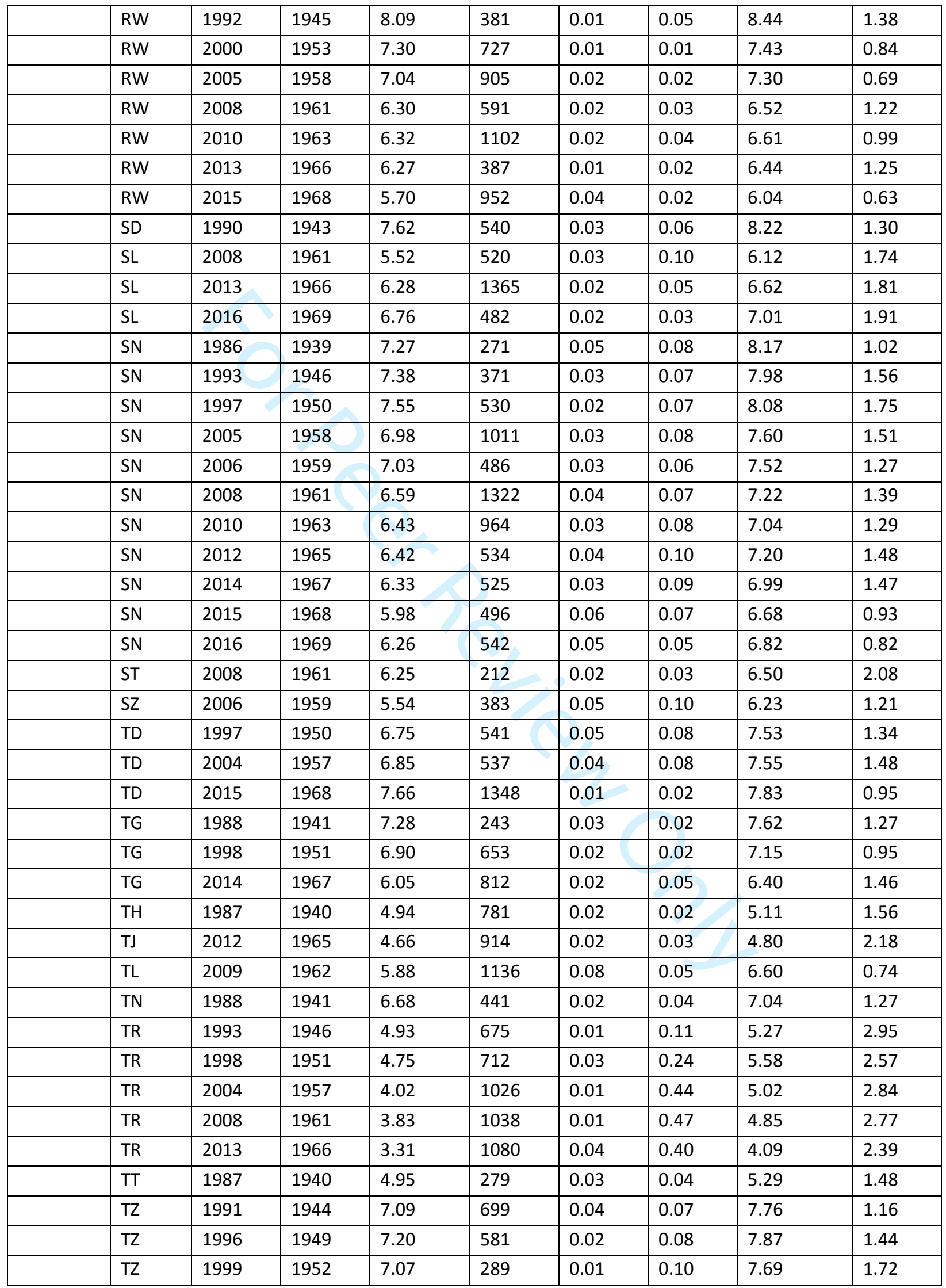




\begin{tabular}{|c|c|c|c|c|c|c|c|c|c|}
\hline & $\mathrm{TZ}$ & 2004 & 1957 & 7.00 & 433 & 0.01 & 0.07 & 7.46 & 1.67 \\
\hline & $\mathrm{TZ}$ & 2004 & 1957 & 6.92 & 751 & 0.02 & 0.08 & 7.48 & 1.47 \\
\hline & $\mathrm{TZ}$ & 2007 & 1960 & 6.60 & 738 & 0.02 & 0.11 & 7.33 & 1.66 \\
\hline & $\mathrm{TZ}$ & 2010 & 1963 & 6.57 & 824 & 0.03 & 0.07 & 7.11 & 1.53 \\
\hline & $\mathrm{TZ}$ & 2012 & 1965 & 6.32 & 844 & 0.03 & 0.11 & 7.00 & 1.84 \\
\hline & $\mathrm{TZ}$ & 2015 & 1968 & 6.23 & 1035 & 0.01 & 0.06 & 6.62 & 1.46 \\
\hline & UA & 2007 & 1960 & 1.84 & 1082 & 0.02 & 0.84 & 2.25 & 1.79 \\
\hline & UG & 1988 & 1941 & 7.86 & 287 & 0.05 & 0.08 & 8.83 & 1.39 \\
\hline & UG & 1995 & 1948 & 7.50 & 351 & 0.02 & 0.09 & 8.23 & 1.64 \\
\hline & UG & 2000 & 1953 & 7.09 & 406 & 0.04 & 0.06 & 7.74 & 1.11 \\
\hline & UG & 2006 & 1959 & 7.71 & 602 & 0.04 & 0.03 & 8.20 & 0.89 \\
\hline & UG & 2009 & 1962 & 7.15 & 274 & 0.02 & 0.06 & 7.61 & 2.02 \\
\hline & UG & 2011 & 1964 & 7.31 & 562 & 0.03 & 0.08 & 7.97 & 1.65 \\
\hline & UG & 2011 & 1964 & 7.26 & 842 & 0.03 & 0.10 & 8.03 & 1.77 \\
\hline & UG & 2014 & 1967 & 7.46 & 307 & 0.00 & 0.03 & 7.63 & 1.90 \\
\hline 19401888 & US & 1940 & 1888 & 3.15 & 3515 & 0.07 & 0.06 & 3.46 & 1.22 \\
\hline 19401893 & US & 1940 & 1893 & 2.96 & 4081 & 0.03 & 0.08 & 3.14 & 1.54 \\
\hline 19501898 & US & 1950 & 1898 & 2.69 & 5000 & 0.03 & 0.13 & 2.87 & 2.02 \\
\hline 19501903 & US & 1950 & 1903 & 2.43 & 5000 & 0.03 & 0.21 & 2.65 & 2.04 \\
\hline 19601908 & US & 1960 & 1908 & 2.26 & 5000 & 0.03 & 0.26 & 2.50 & 1.98 \\
\hline 19601913 & US & 1960 & 1913 & 2.27 & 5000 & 0.03 & 0.29 & 2.50 & 2.05 \\
\hline 19701918 & US & 1970 & 1918 & 2.54 & 5000 & 0.01 & 0.33 & 2.67 & 2.41 \\
\hline 19701923 & US & 1970 & 1923 & 2.77 & 5000 & 0.01 & 0.37 & 2.94 & 2.62 \\
\hline 19801928 & US & 1980 & 1928 & 2.96 & 5000 & 0.03 & 0.36 & 3.22 & 2.63 \\
\hline 19801933 & US & 1980 & 1933 & 3.13 & 5000 & 0.04 & 0.34 & 3.47 & 2.62 \\
\hline 19901938 & US & 1990 & 1938 & 2.84 & 5000 & 0.04 & 0.42 & 3.07 & 2.61 \\
\hline \multirow[t]{17}{*}{19901943} & US & 1990 & 1943 & 2.42 & 5000 & 0.04 & 0.52 & 2.41 & 2.48 \\
\hline & UZ & 1996 & 1949 & 4.45 & 324 & 0.02 & 0.09 & 4.83 & 1.86 \\
\hline & UZ & 2002 & 1955 & 4.44 & 455 & 0.03 & 0.03 & 4.64 & 1.28 \\
\hline & VN & 1997 & 1950 & 4.46 & 614 & 0.01 & 0.04 & 4.56 & 3.07 \\
\hline & VN & 2002 & 1955 & 3.88 & 821 & 0.01 & 0.32 & 4.30 & 3.01 \\
\hline & VN & 2005 & 1958 & 3.23 & 897 & 0.03 & 0.45 & 3.88 & 2.55 \\
\hline & YE & 1991 & 1944 & 7.90 & 524 & 0.01 & 0.06 & 8.31 & 1.86 \\
\hline & YE & 2013 & 1966 & 7.29 & 1542 & 0.03 & 0.06 & 7.81 & 1.40 \\
\hline & $\mathrm{ZA}$ & 1998 & 1951 & 4.20 & 966 & 0.02 & 0.02 & 4.33 & 1.47 \\
\hline & ZM & 1992 & 1945 & 8.03 & 390 & 0.02 & 0.06 & 8.54 & 1.41 \\
\hline & ZM & 1996 & 1949 & 7.80 & 516 & 0.01 & 0.07 & 8.28 & 1.90 \\
\hline & ZM & 2002 & 1955 & 7.47 & 487 & 0.02 & 0.07 & 8.05 & 1.65 \\
\hline & ZM & 2007 & 1960 & 6.71 & 462 & 0.02 & 0.09 & 7.29 & 1.71 \\
\hline & ZM & 2013 & 1966 & 6.72 & 1020 & 0.02 & 0.08 & 7.29 & 1.57 \\
\hline & ZW & 1988 & 1941 & 6.87 & 290 & 0.04 & 0.10 & 7.66 & 1.55 \\
\hline & ZW & 1994 & 1947 & 6.66 & 416 & 0.01 & 0.07 & 7.12 & 1.65 \\
\hline & ZW & 1999 & 1952 & 6.29 & 382 & 0.02 & 0.06 & 6.69 & 1.65 \\
\hline
\end{tabular}




\begin{tabular}{|l|l|l|l|l|l|l|l|l|l|}
\hline & ZW & 2005 & 1958 & 5.70 & 619 & 0.03 & 0.03 & 5.98 & 1.38 \\
\hline & ZW & 2010 & 1963 & 4.99 & 632 & 0.01 & 0.04 & 5.19 & 1.48 \\
\hline & ZW & 2015 & 1968 & 4.12 & 595 & 0.03 & 0.17 & 4.41 & 3.08 \\
\hline
\end{tabular}

Figure S.4. Observed parity distributions (solid lines) by predicted (dashed lines). U.S. Samples.
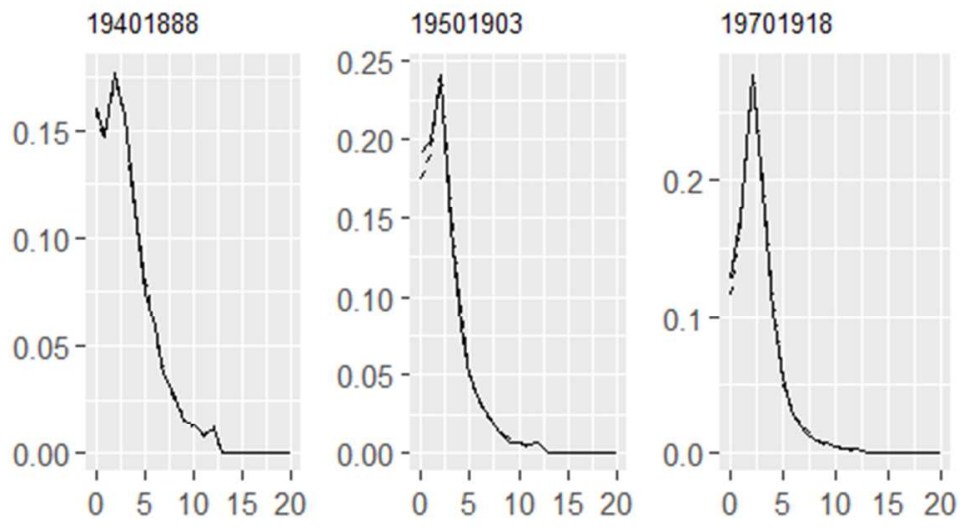

19801933
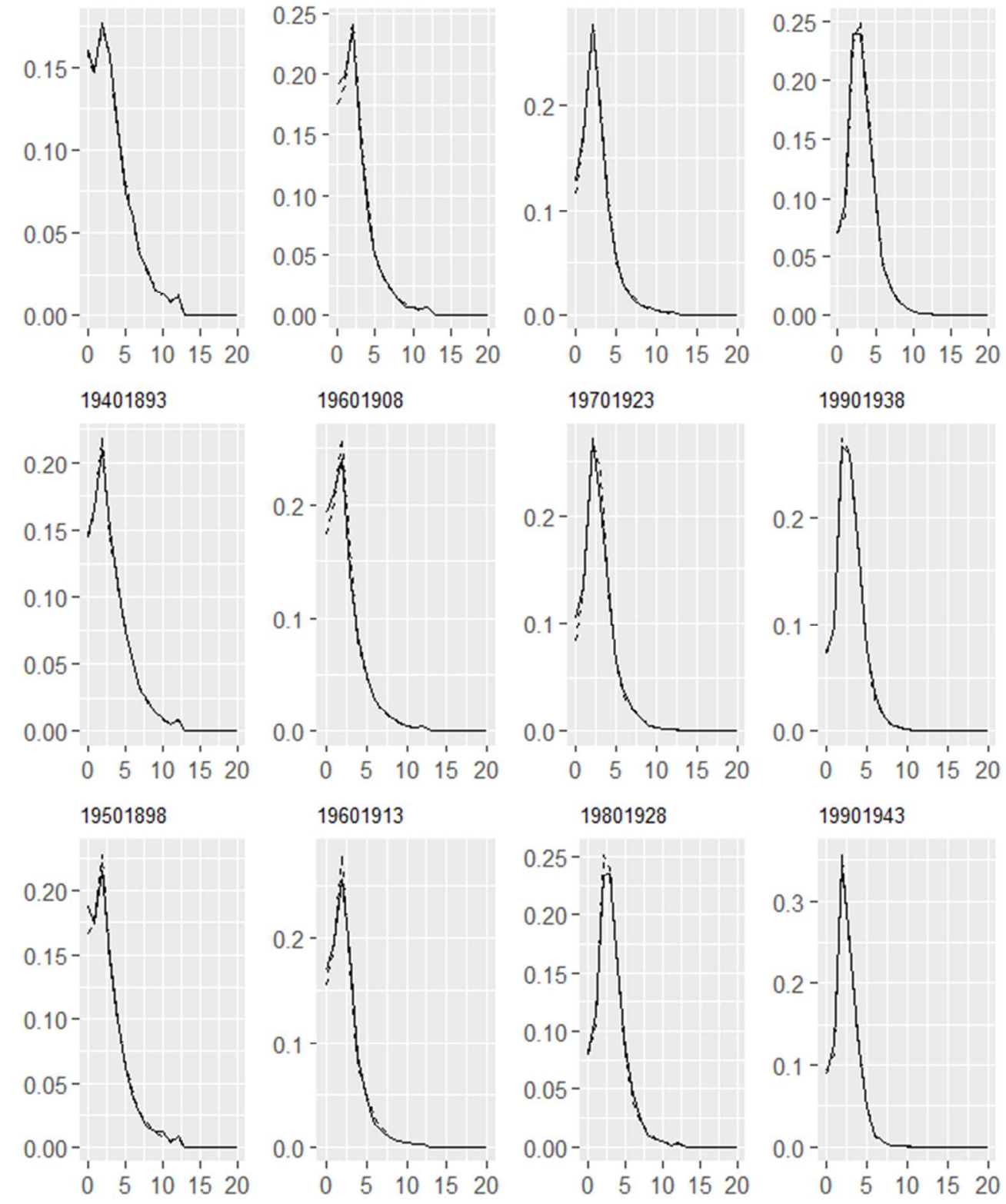
Figure S.5. Observed parity distributions (solid lines) by predicted (dashed lines). DHS Samples.
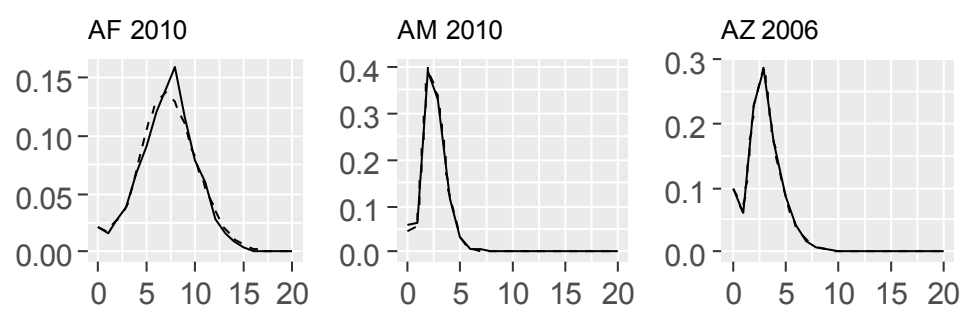

BD 2007

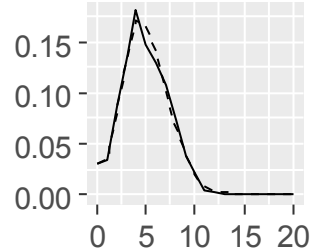

BF 2003
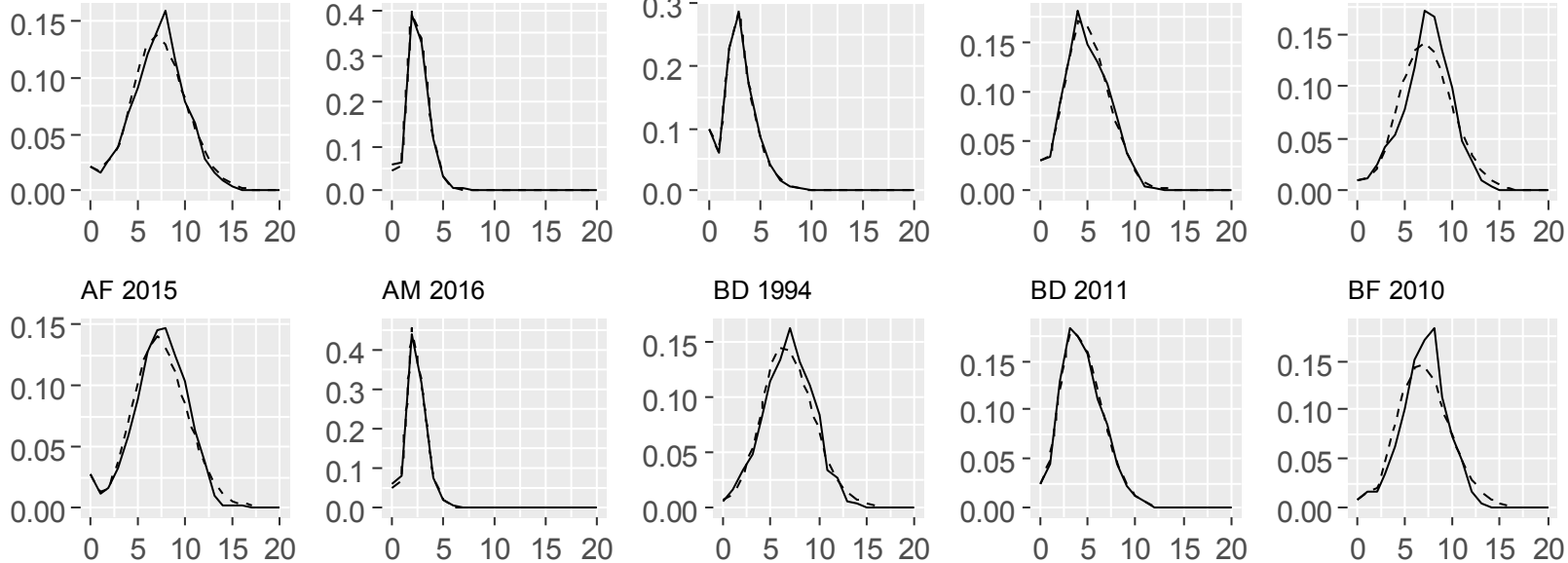

AL 2008

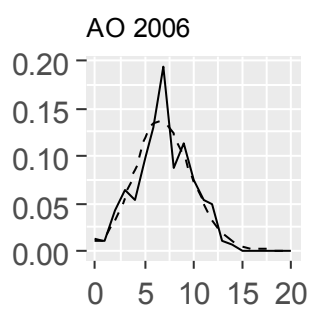

BD 1996

BD 2014
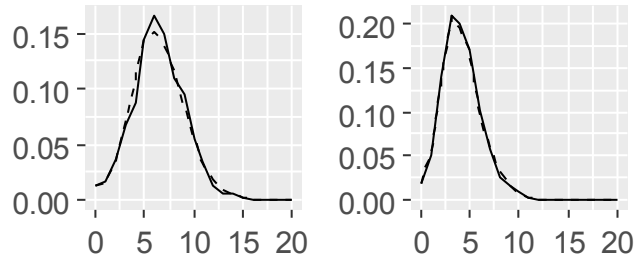

BF 2010

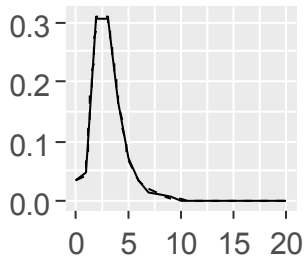

AO 2011

BD 1999

BF 1993
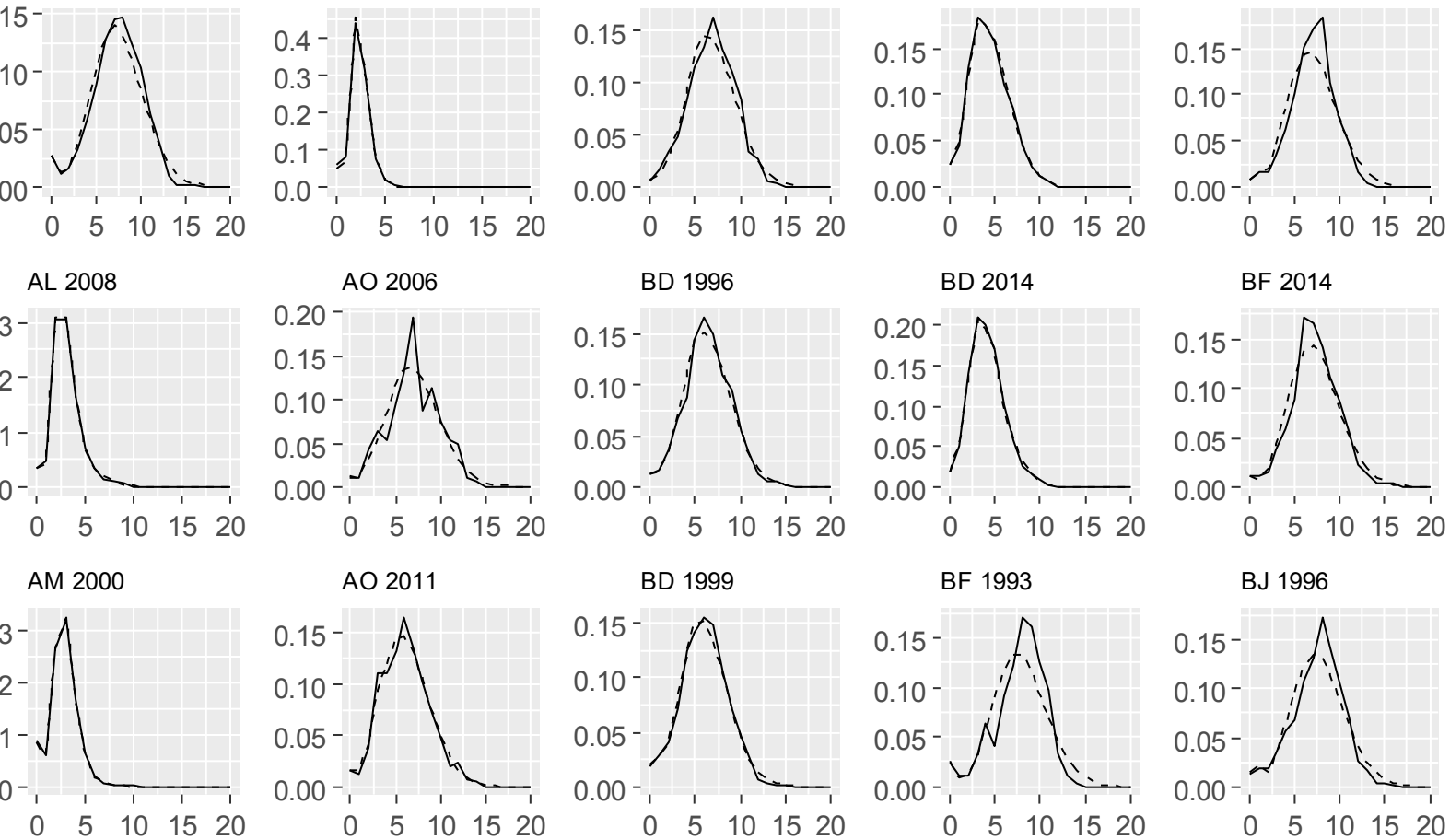

BF 2014
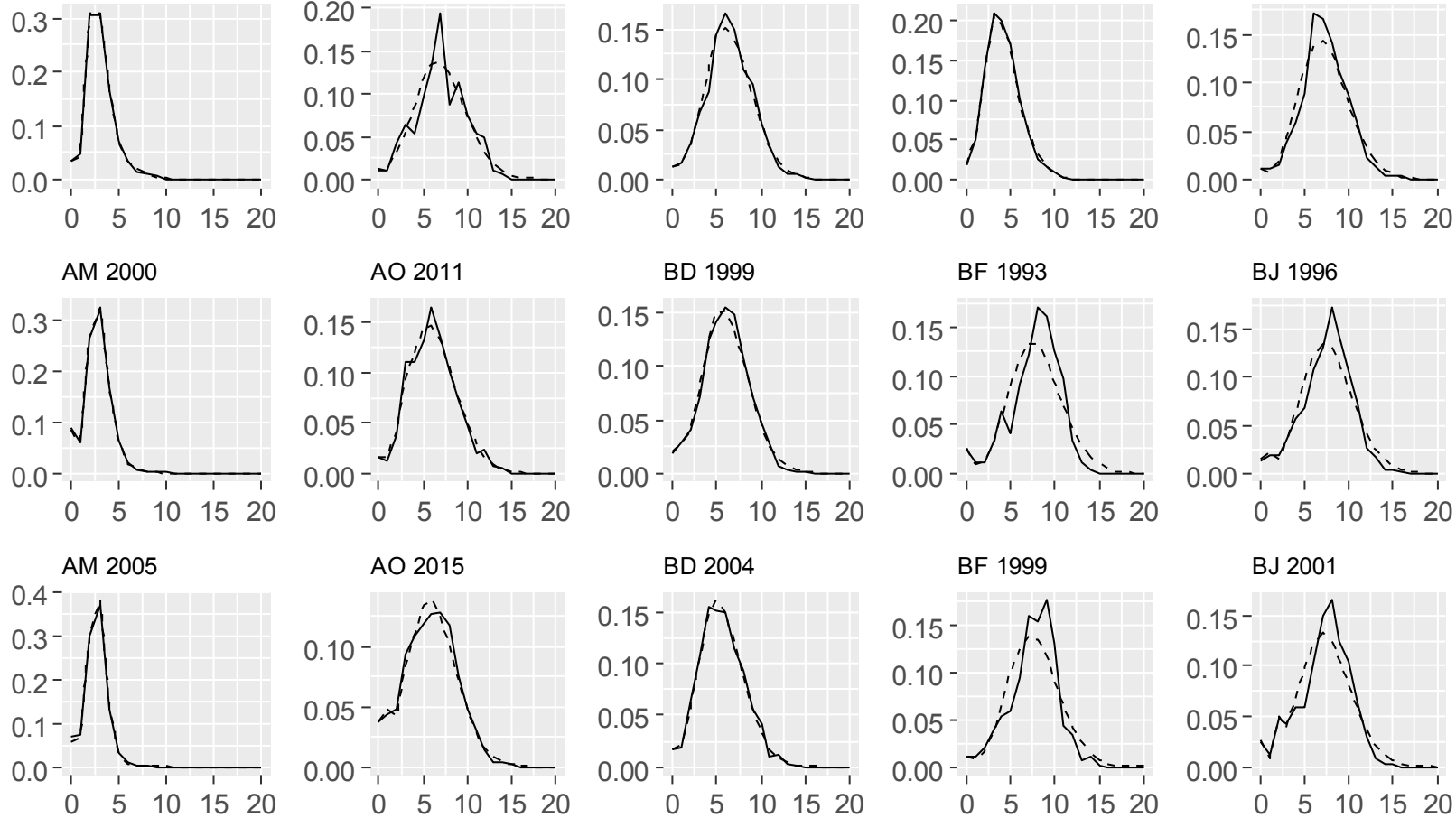

BJ 1996

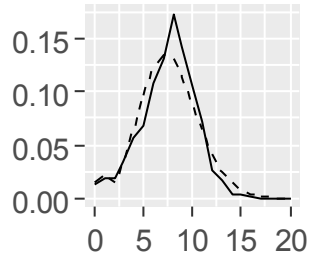

\section{BJ 2001}

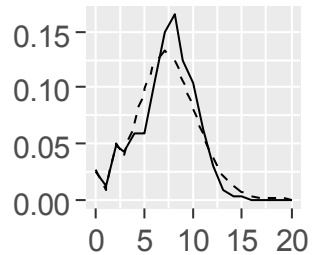



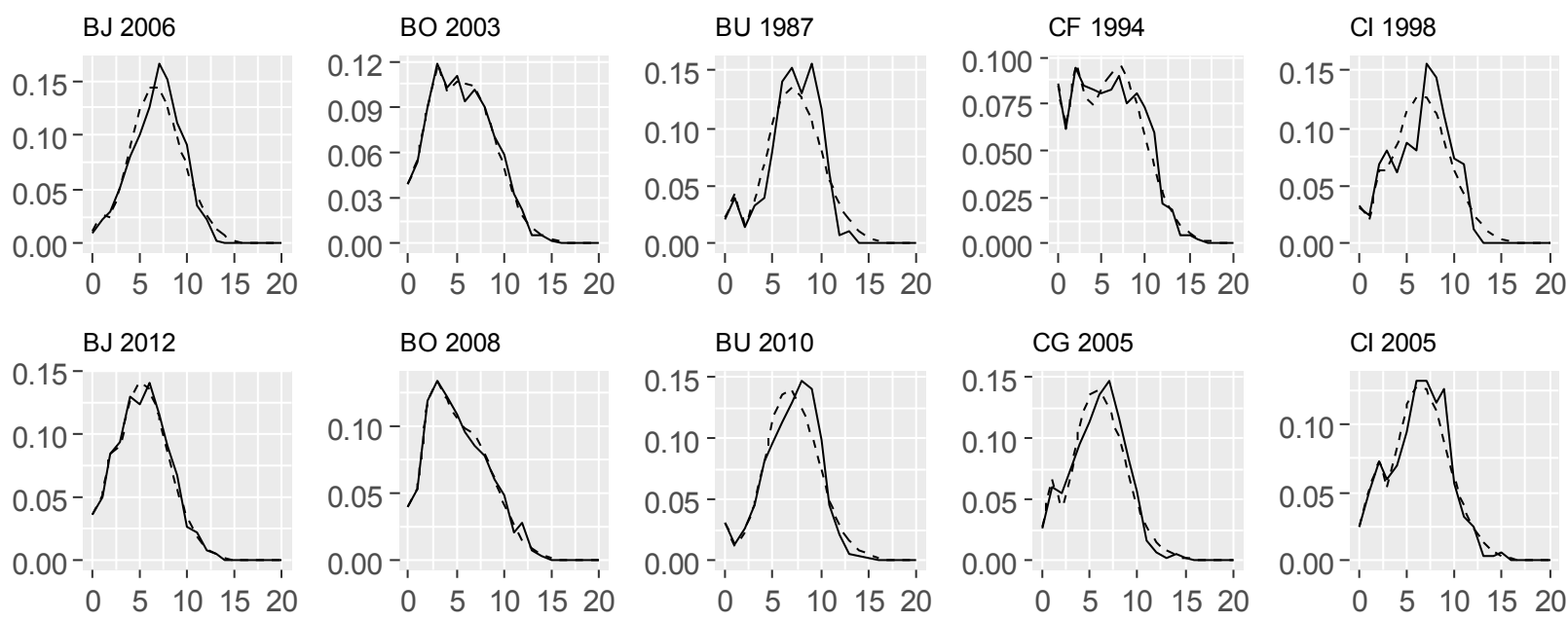

Cl 2005
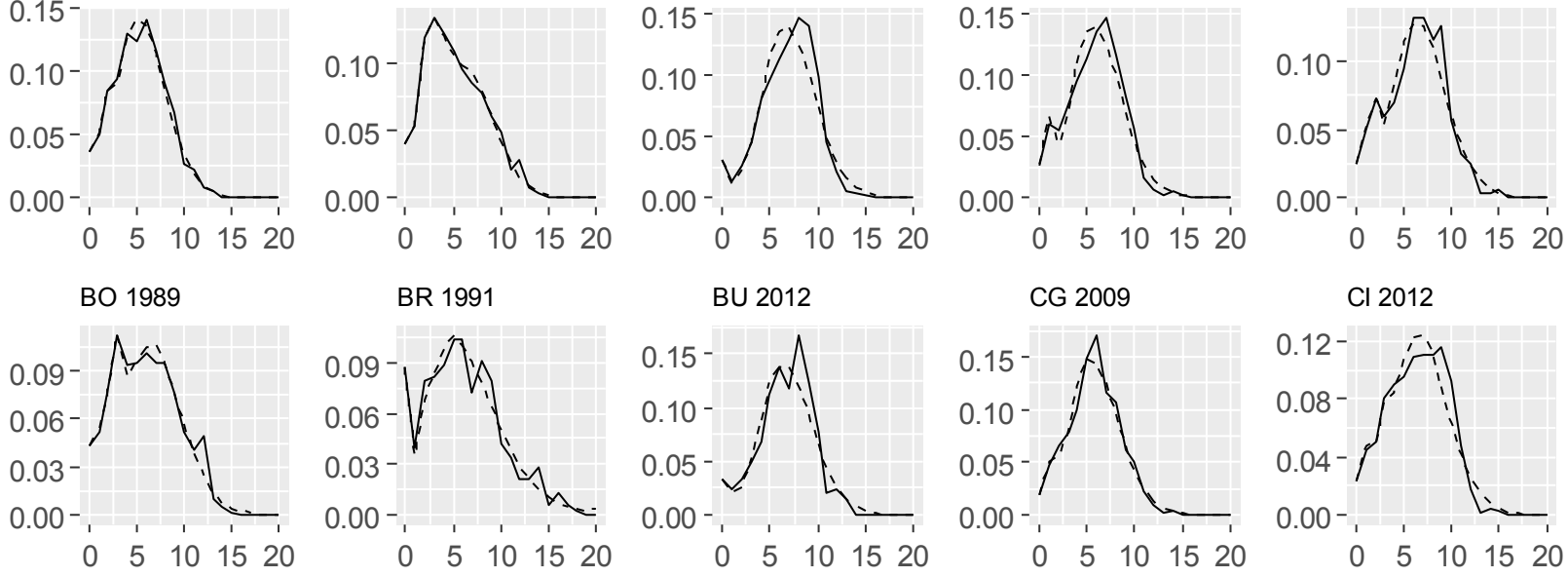

BO 1994
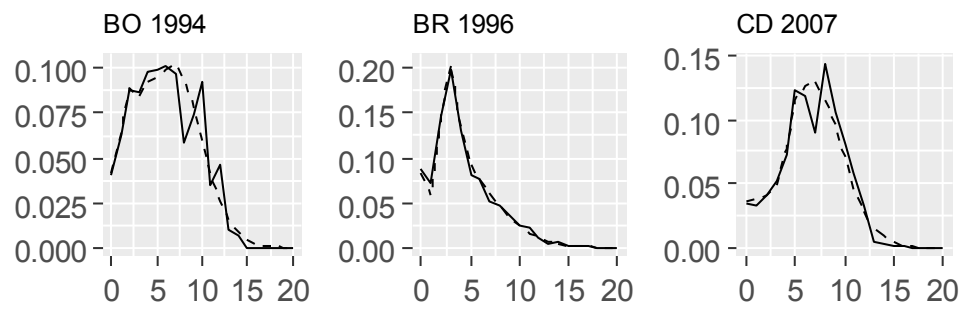

CG 2011

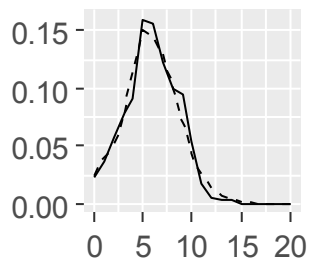

Cl 2012
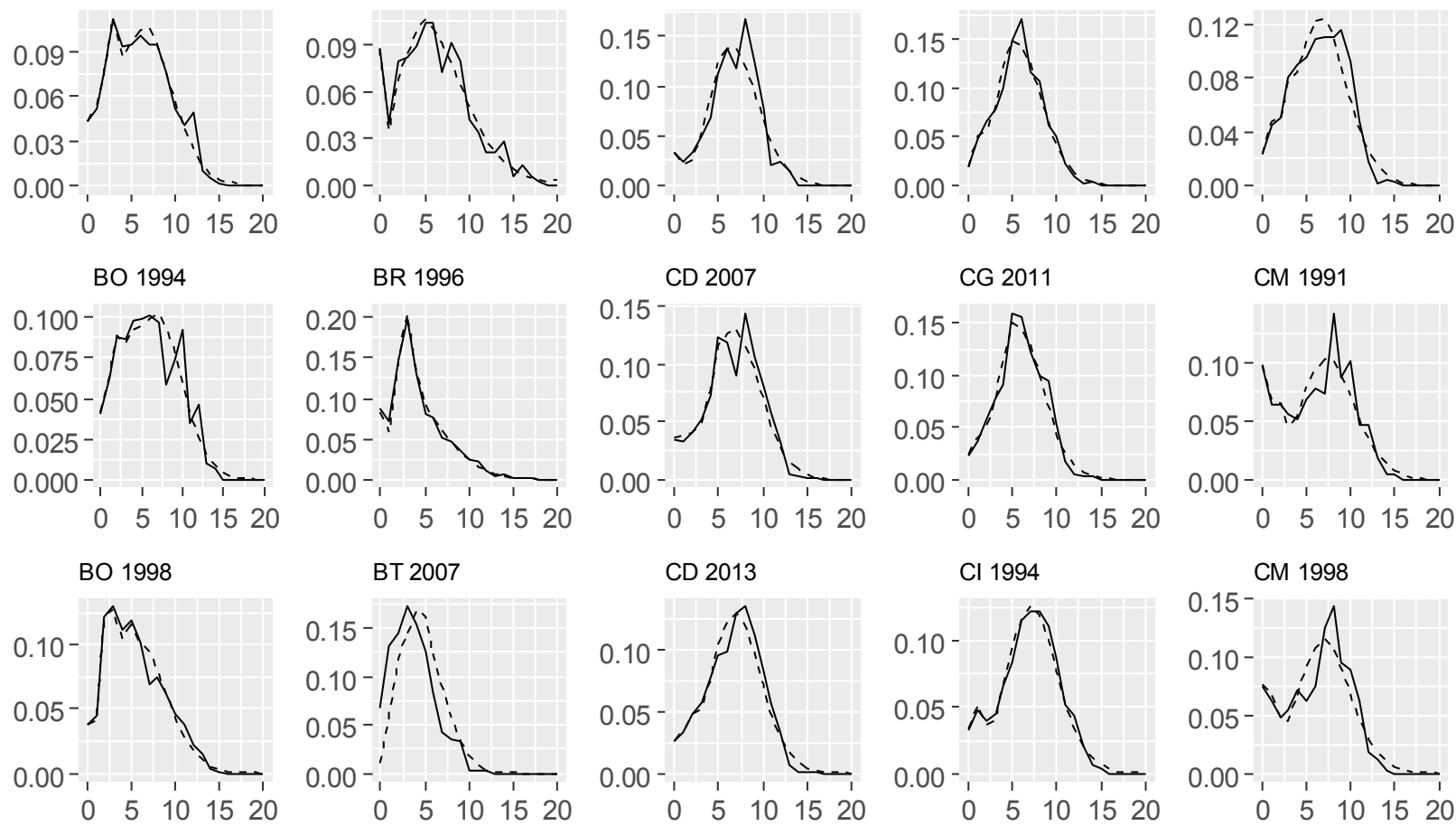

\section{1991}
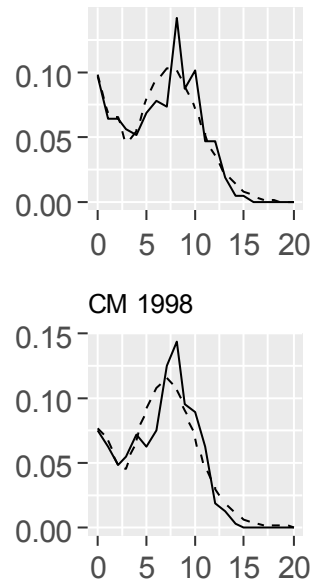

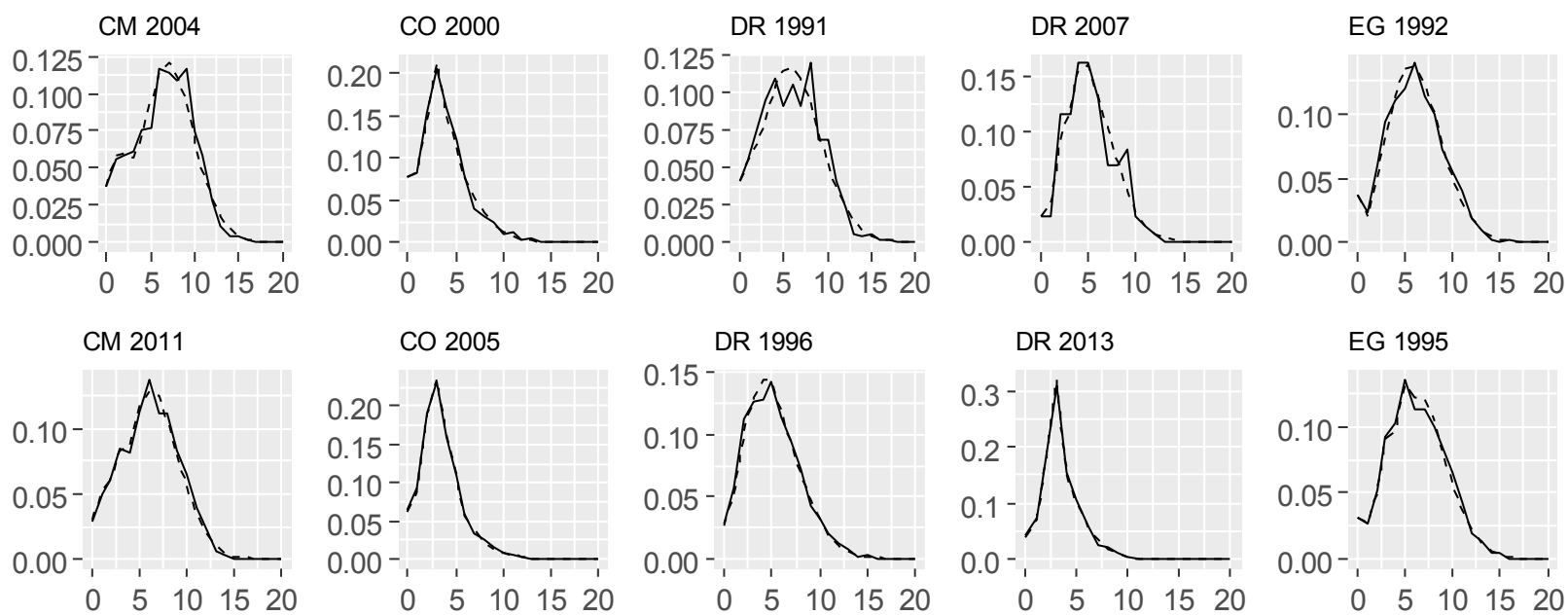

DR 2013

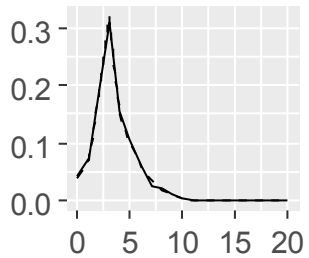

EG 1995
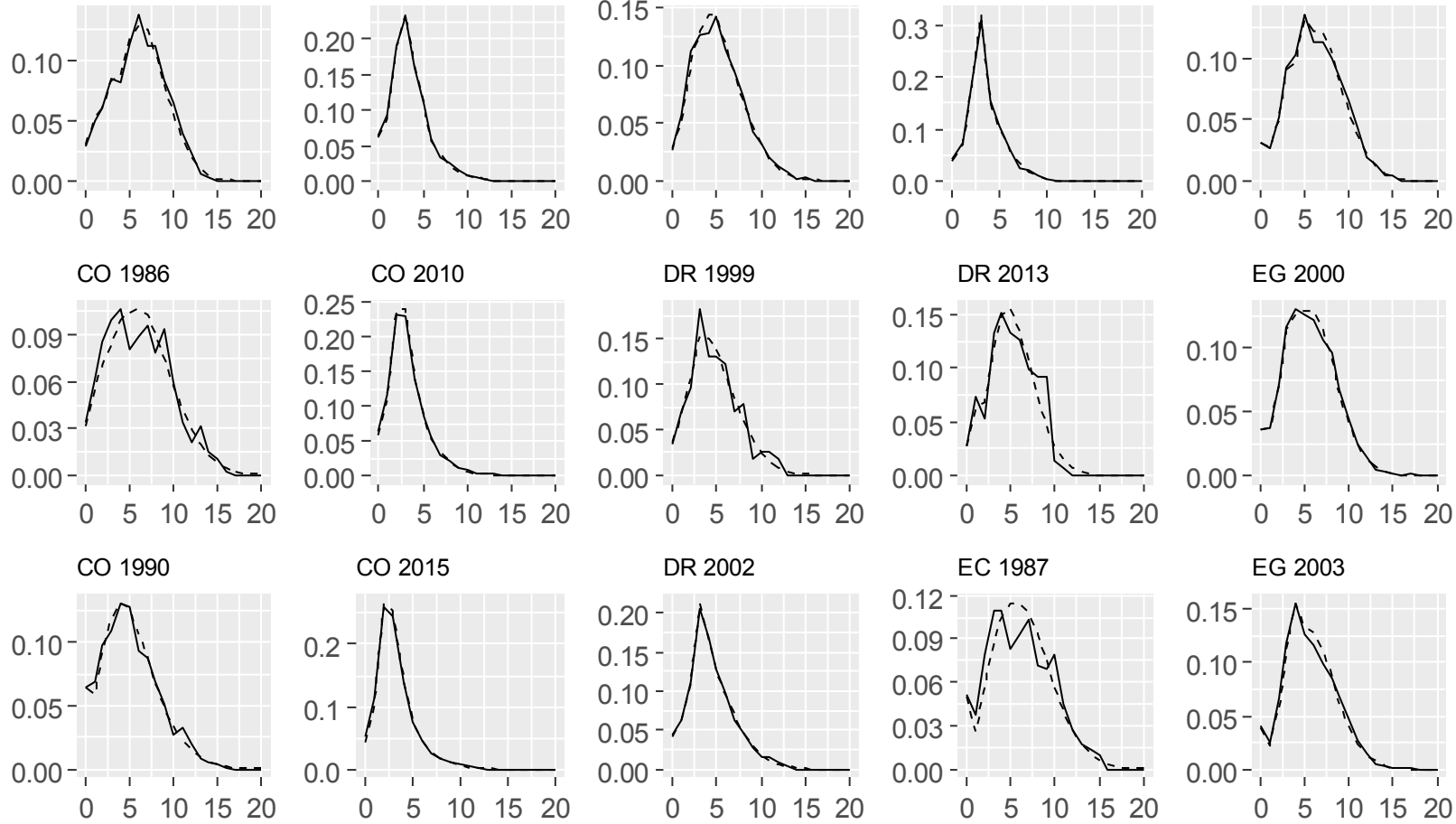

DR 1986

DR 2007
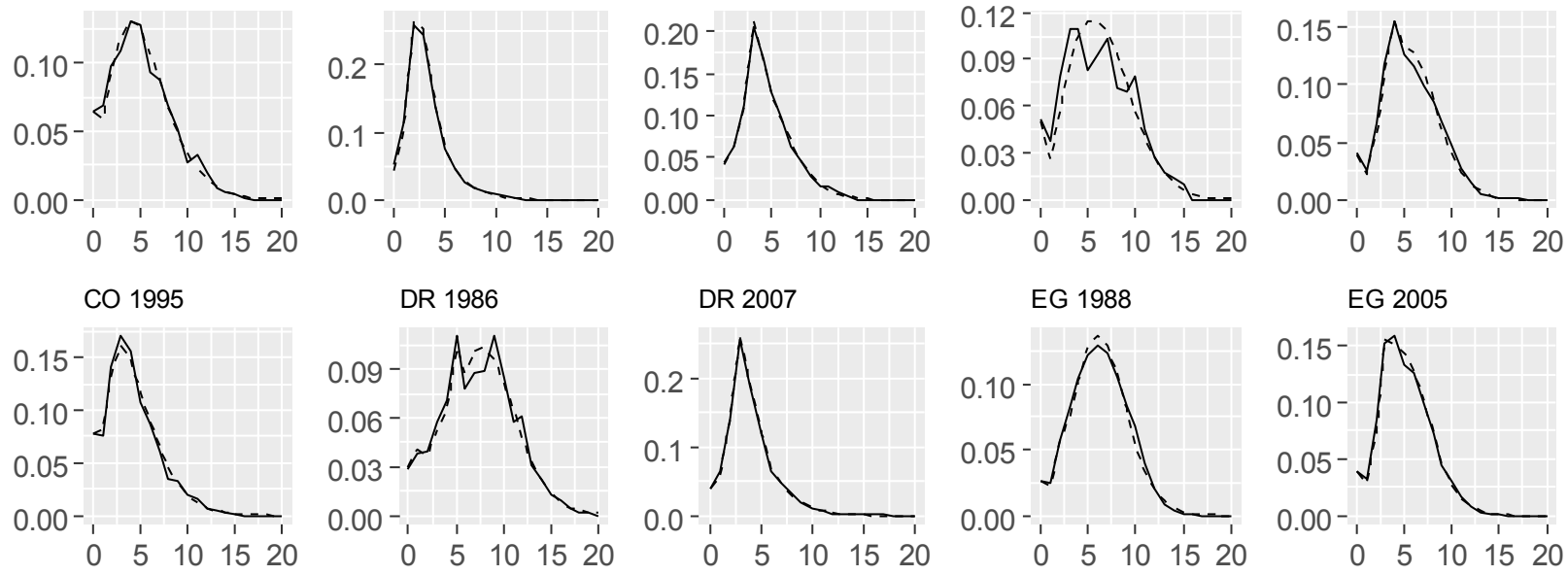

EG 2005

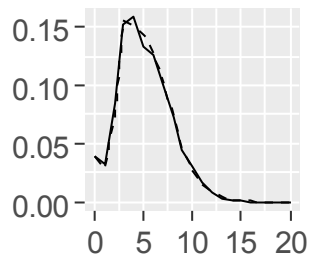



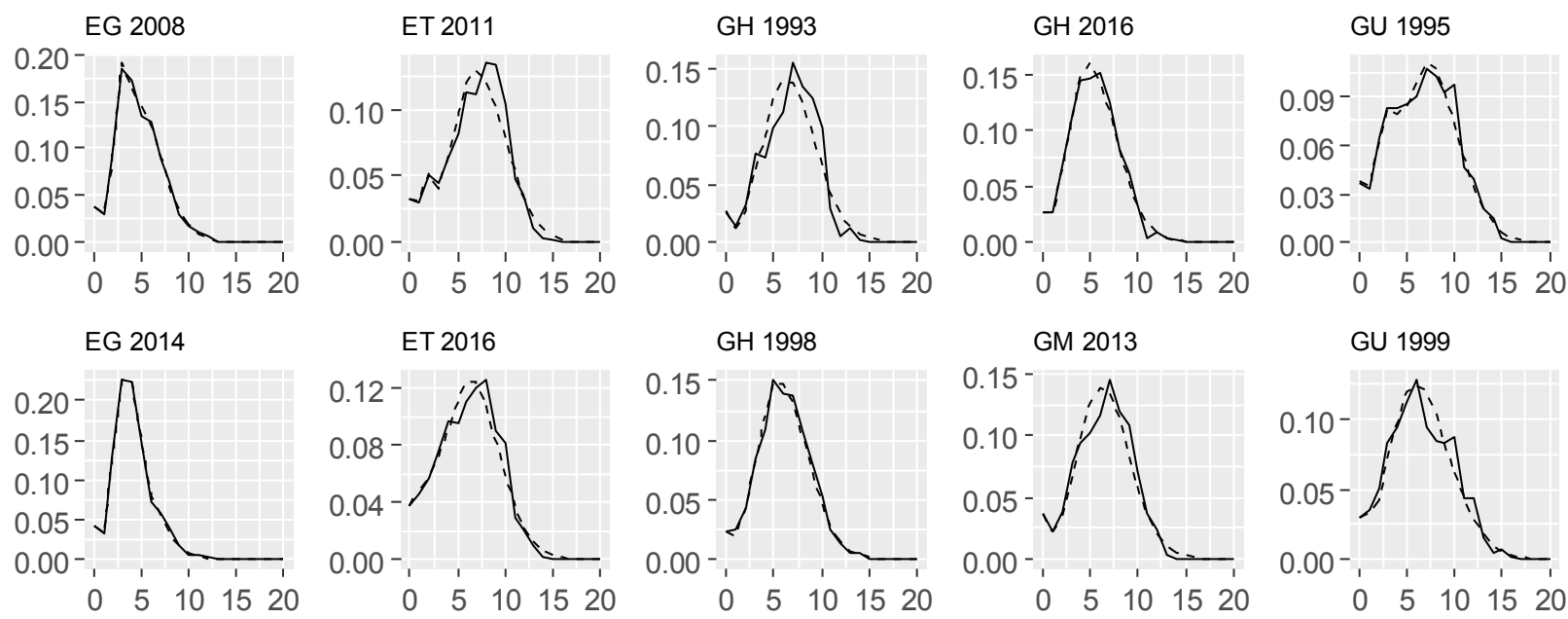

GU 1999
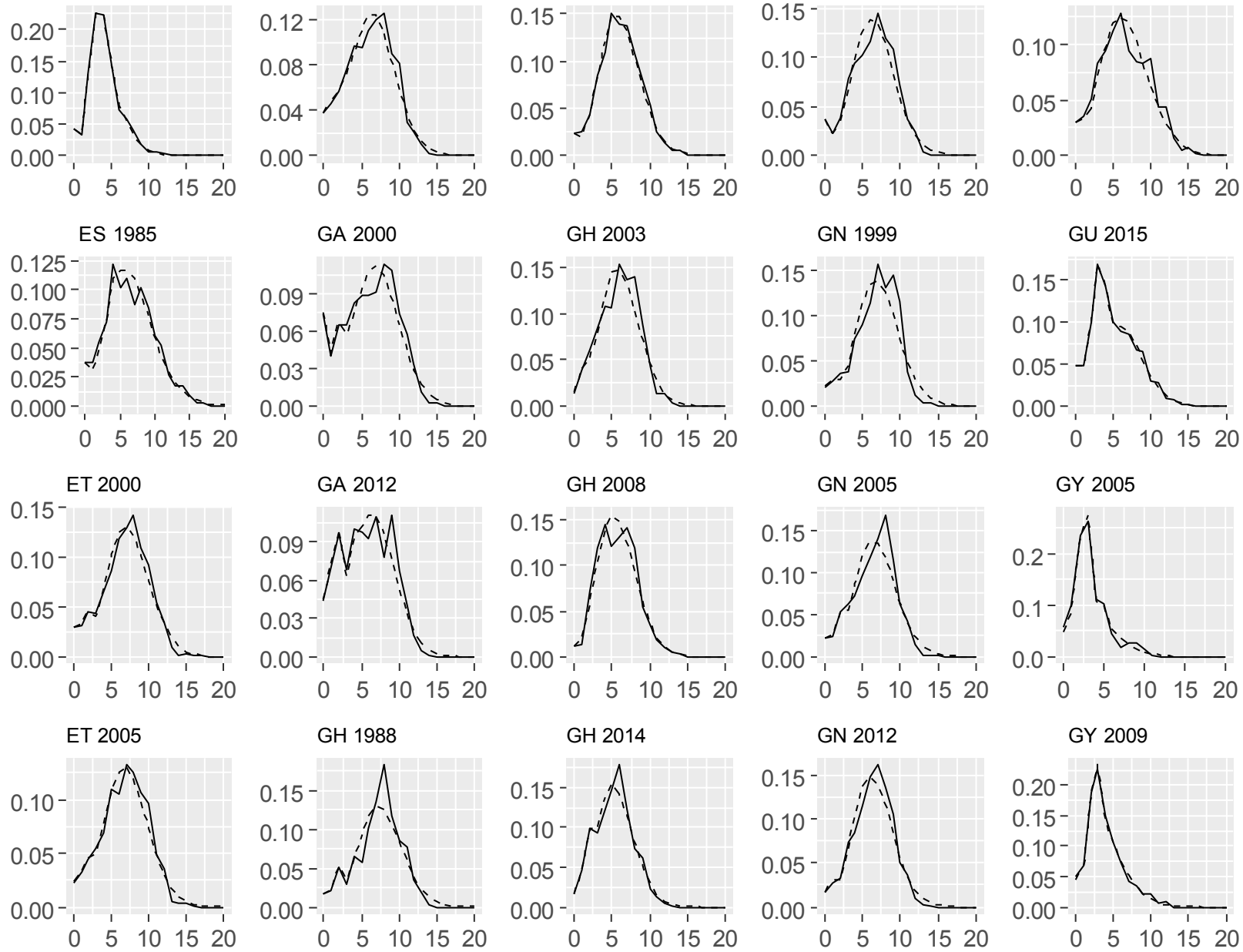

\section{GY 2009}

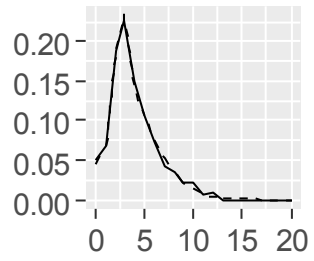



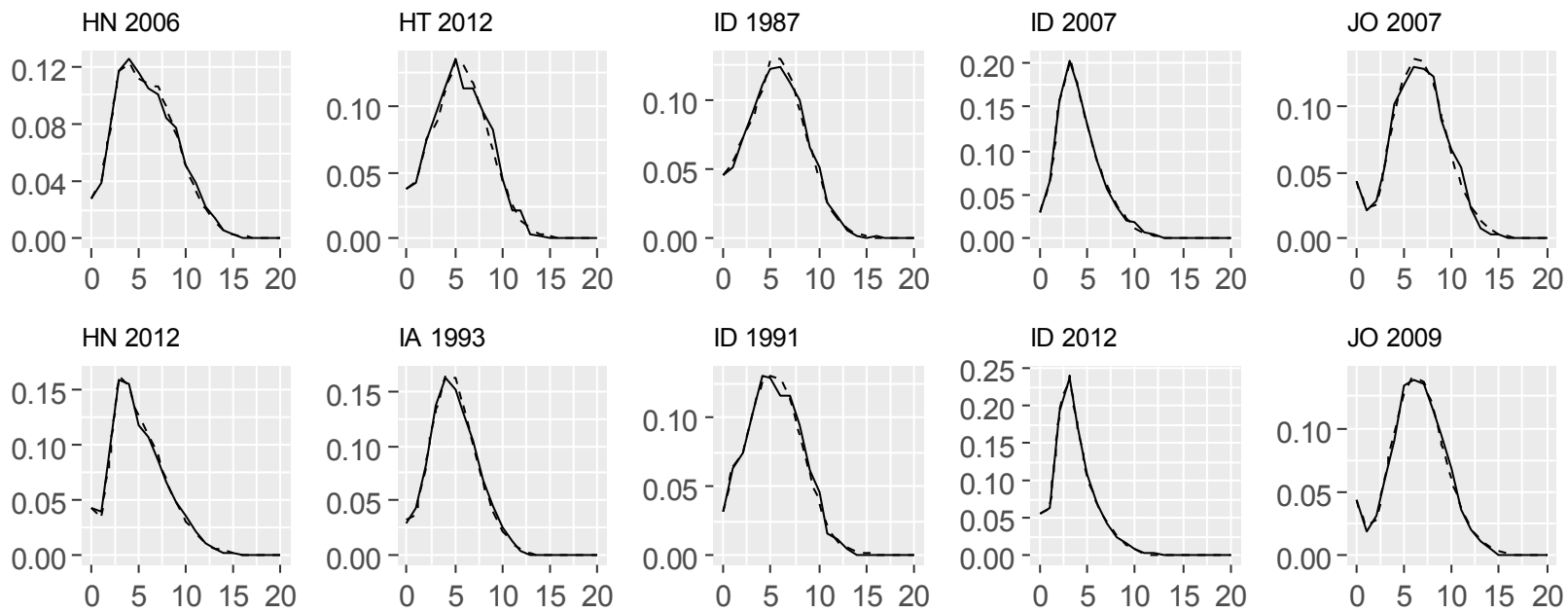

HT 1994

IA 1999
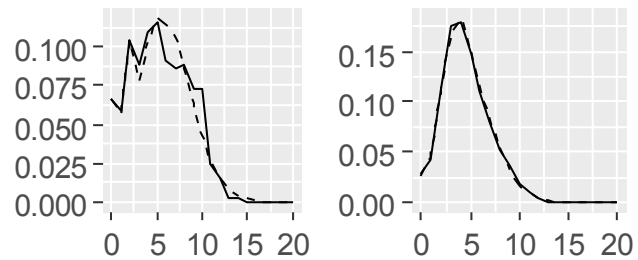

ID 1994

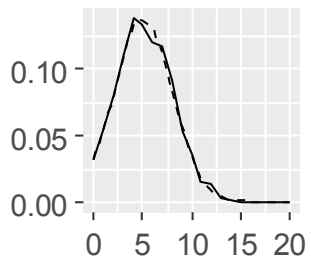

JO 1990
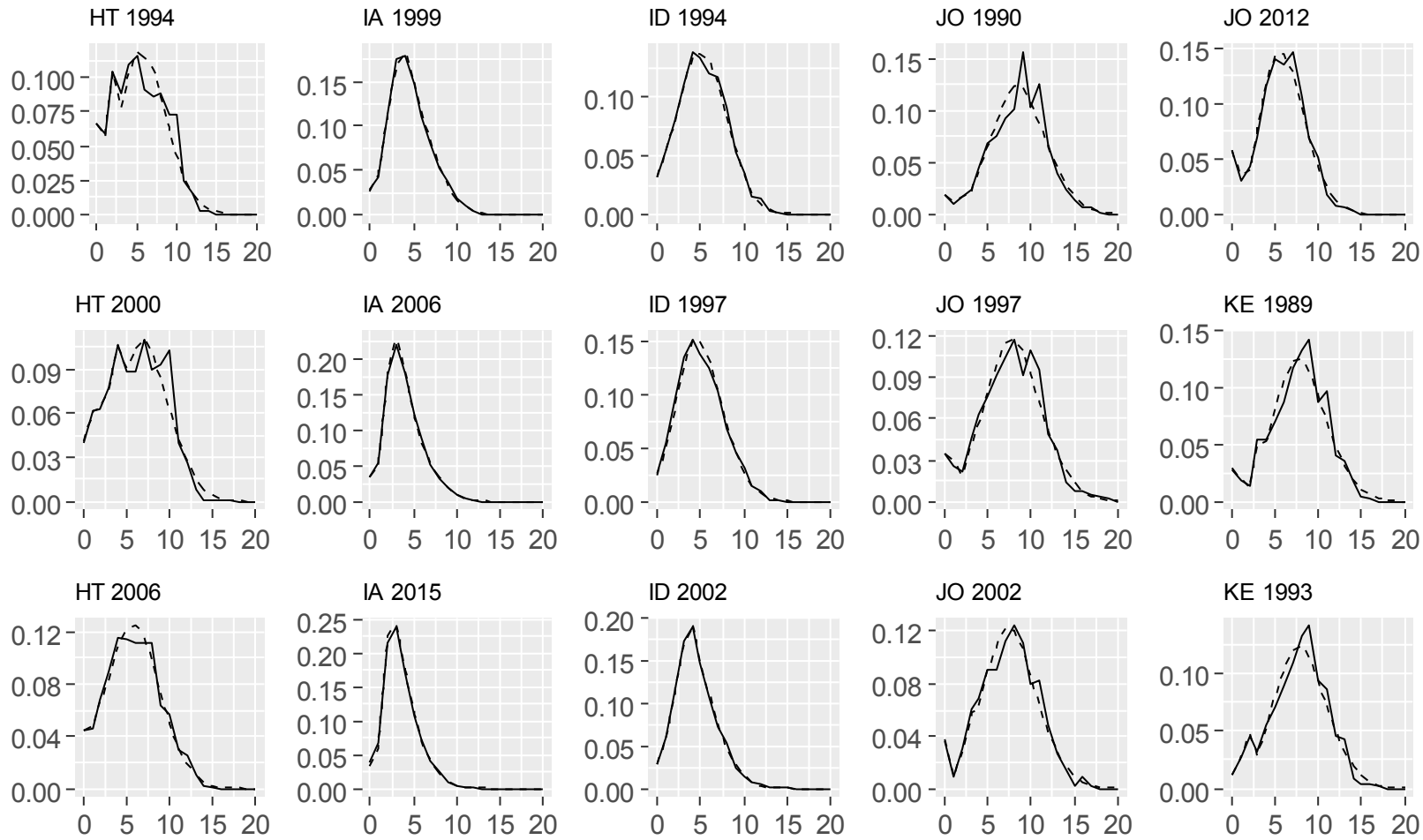

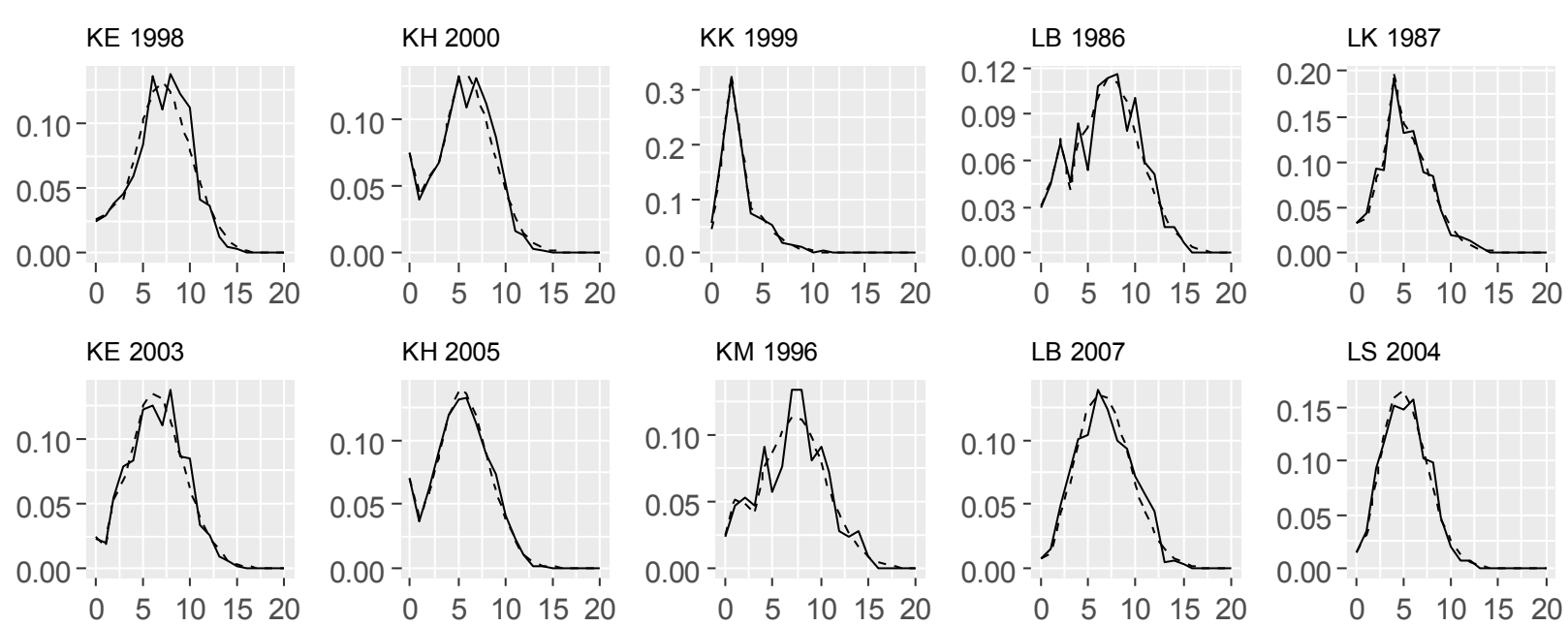

LS 2004
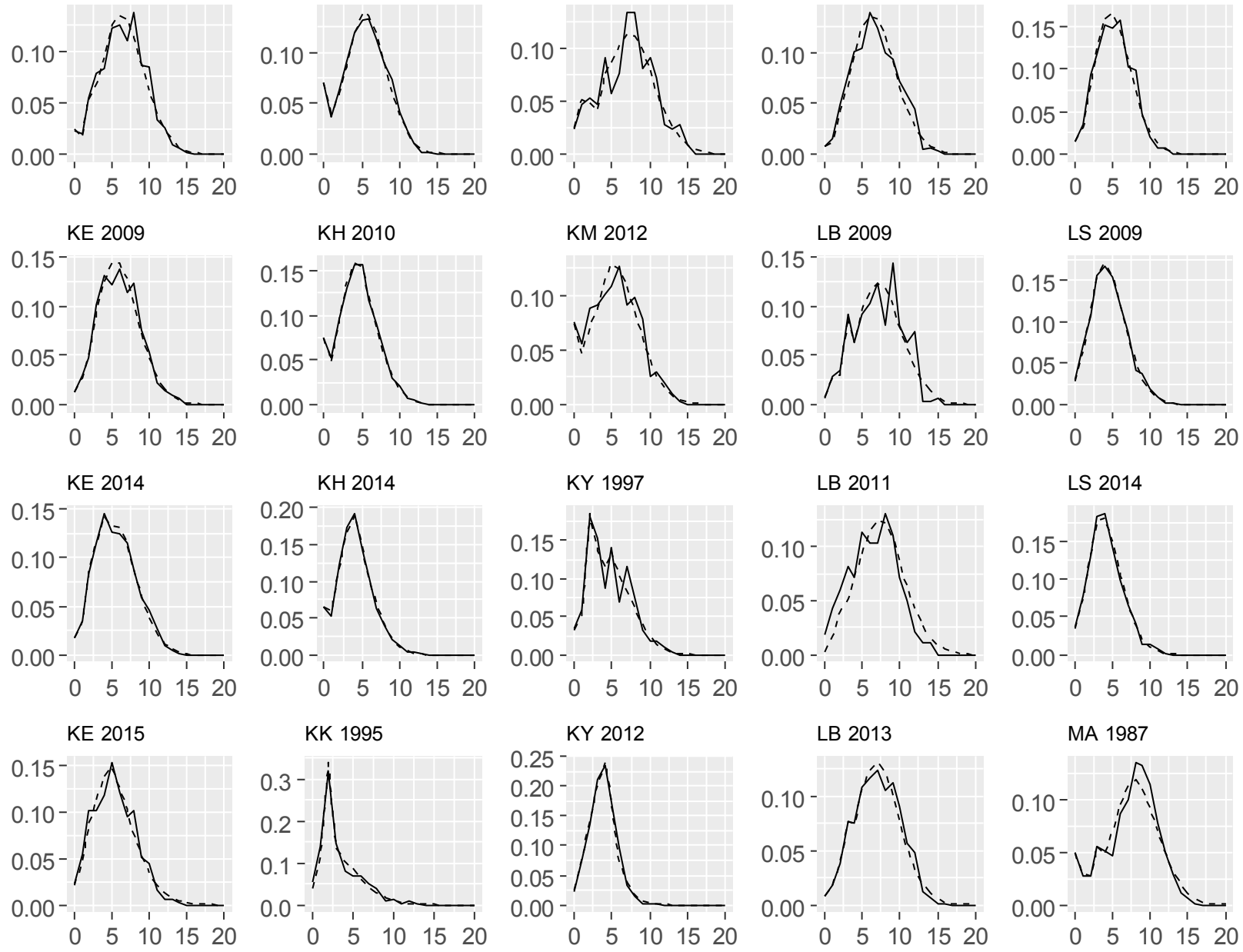

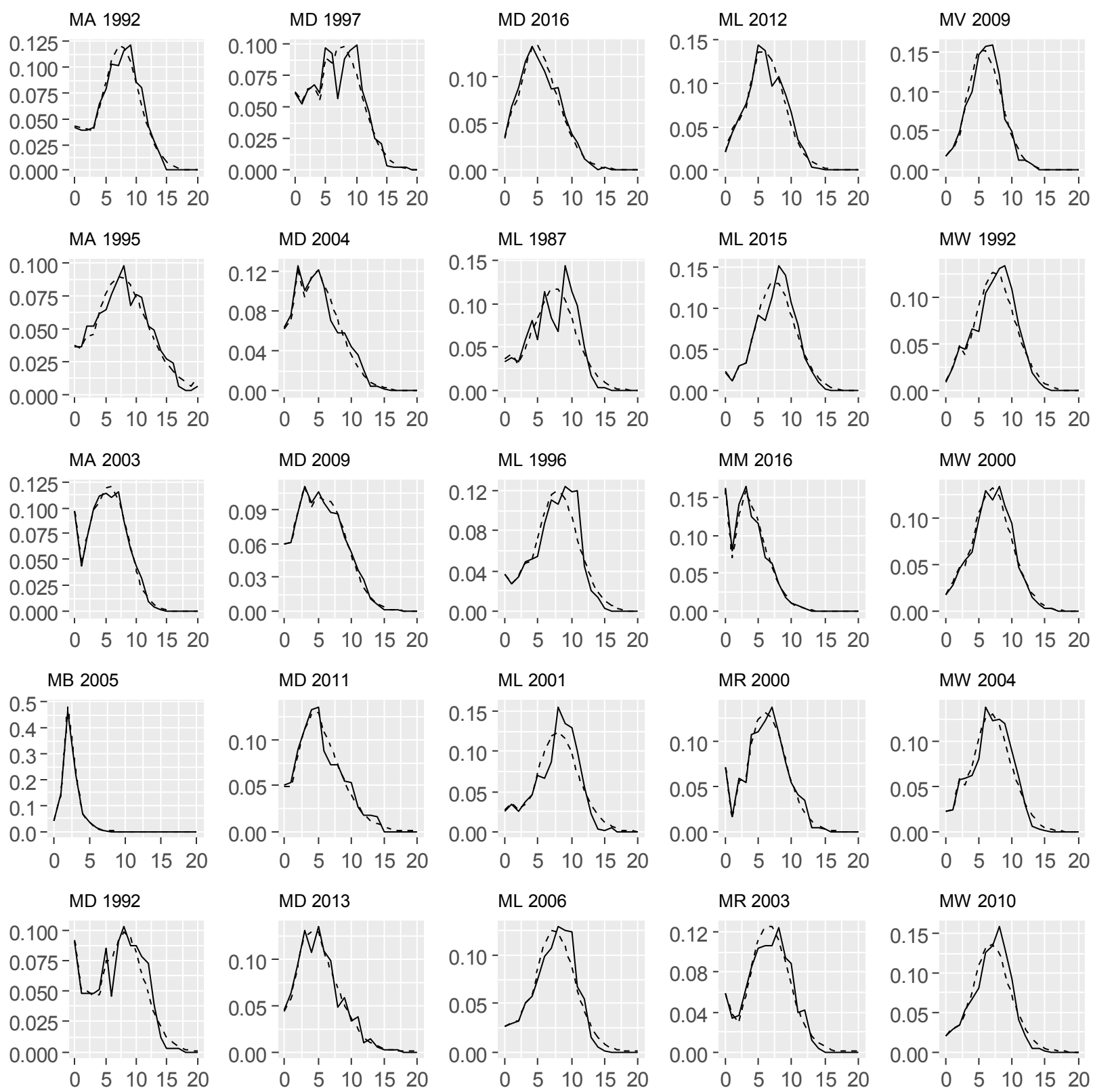

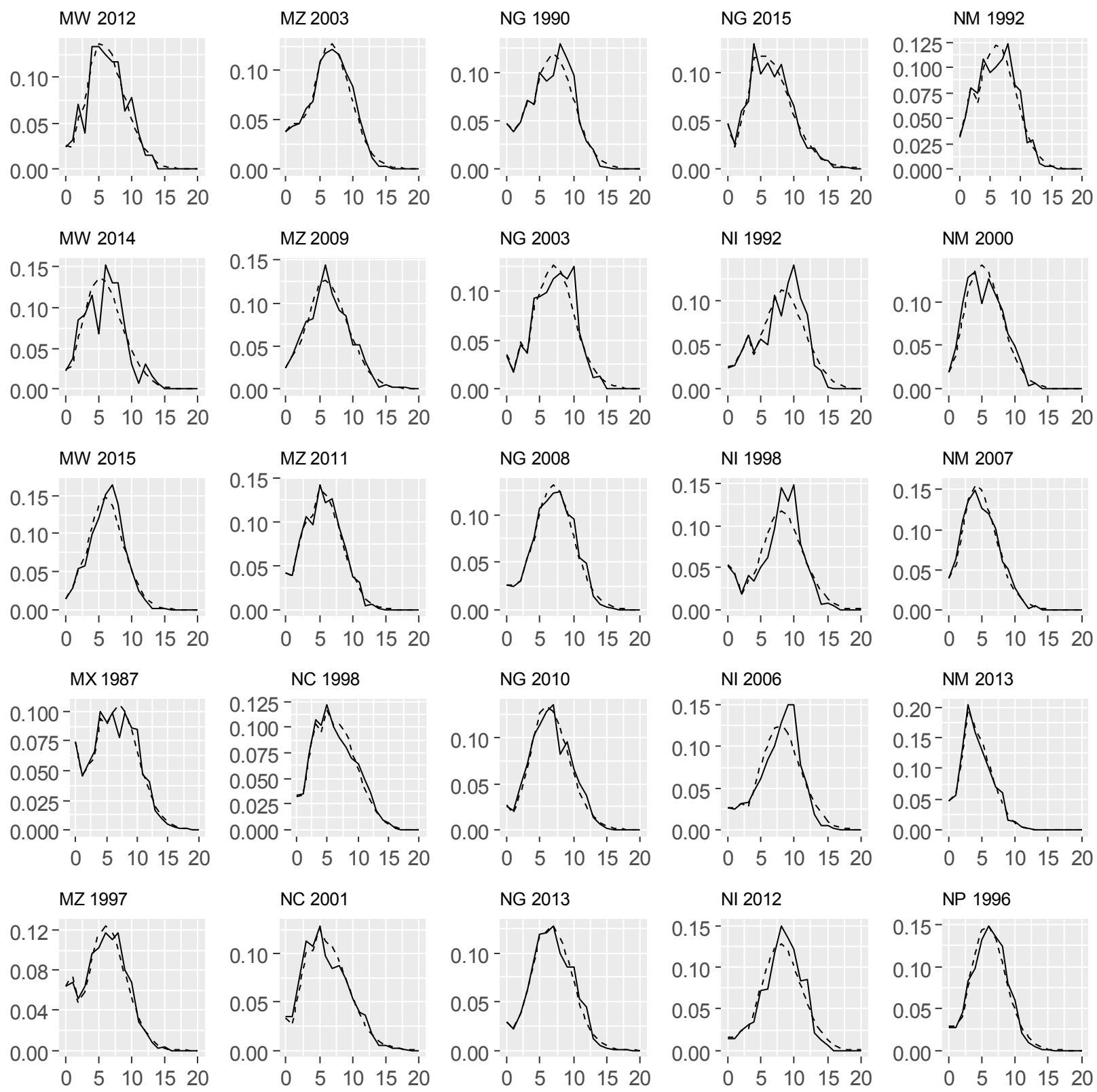

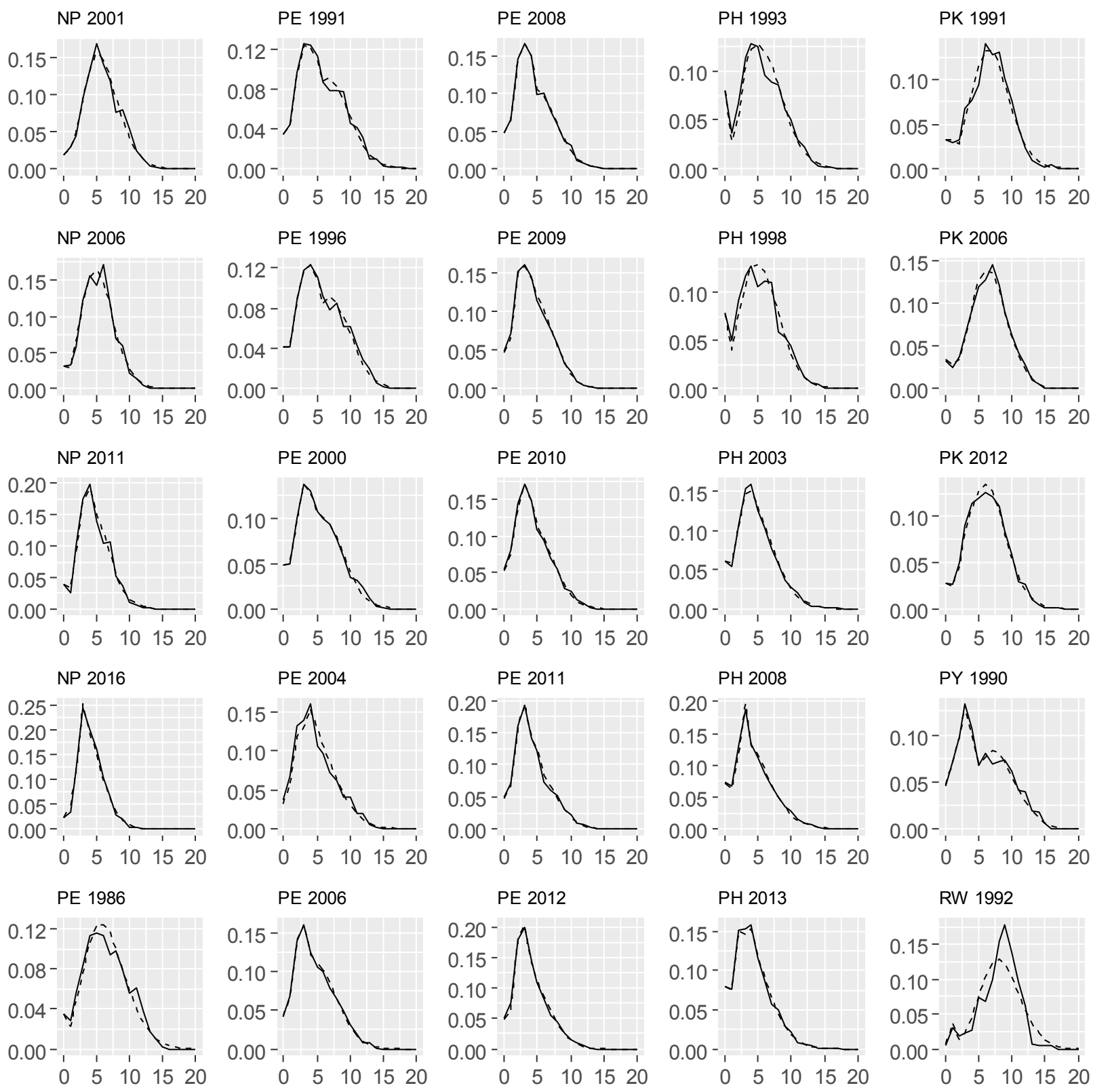

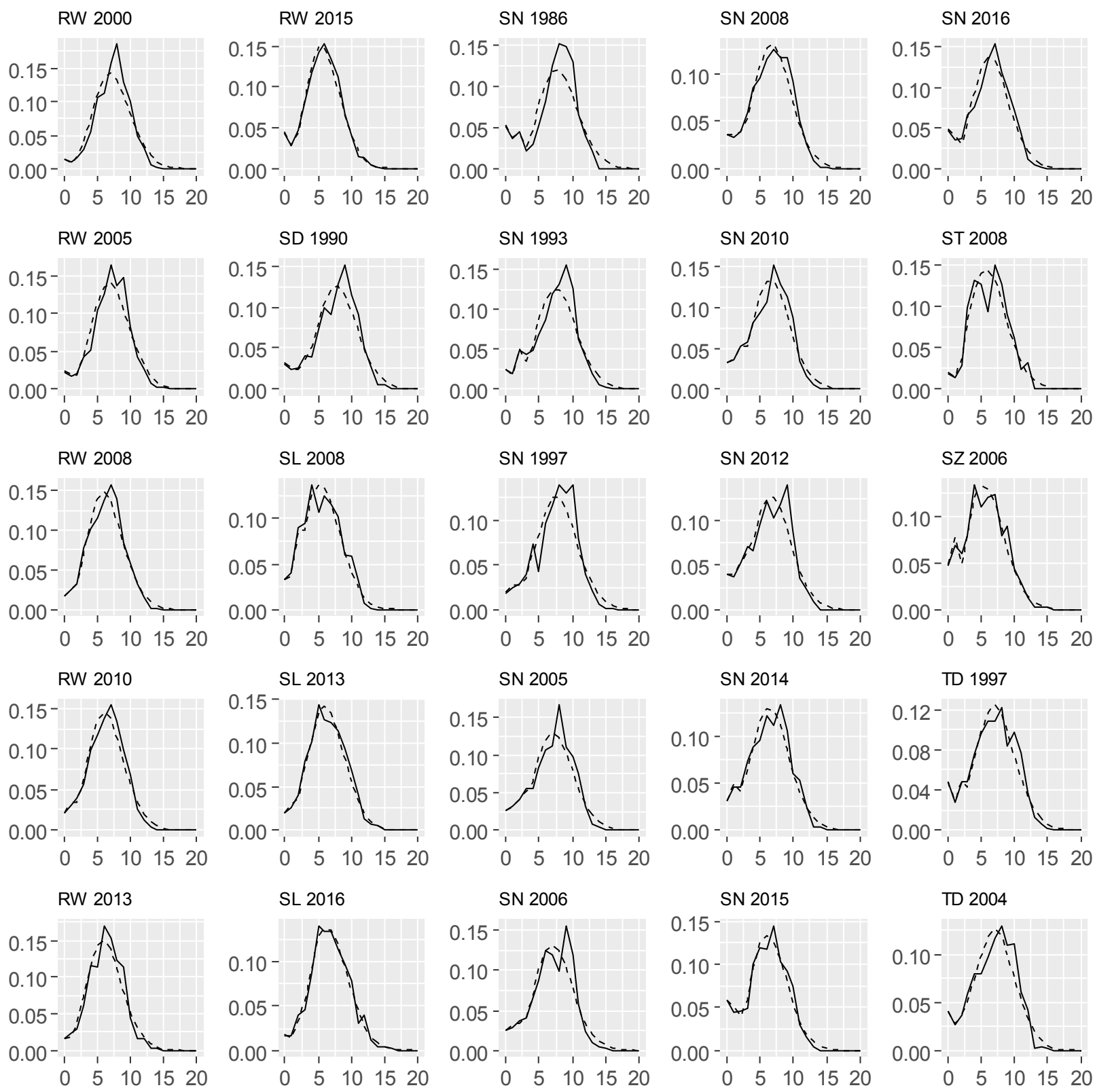

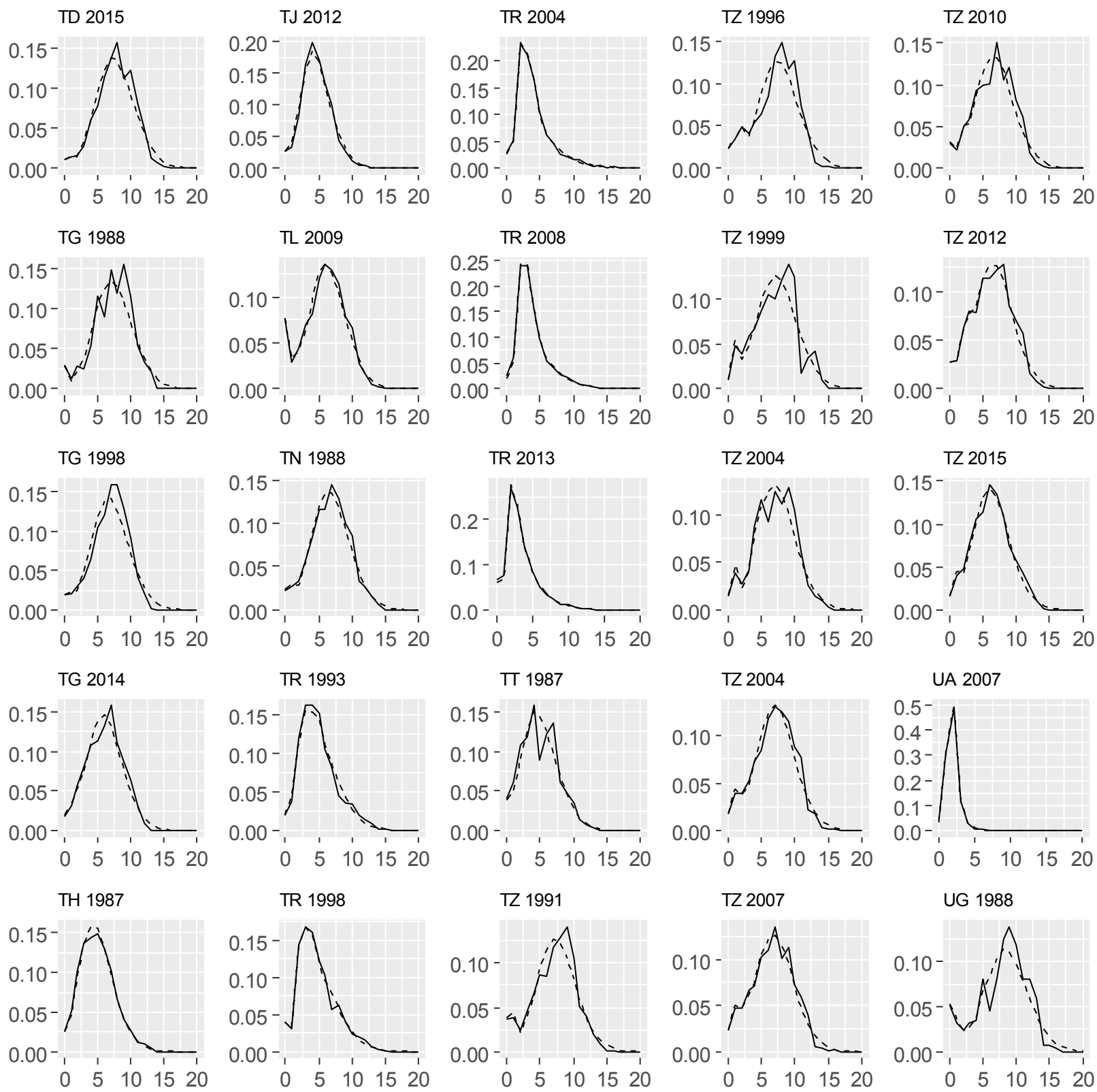

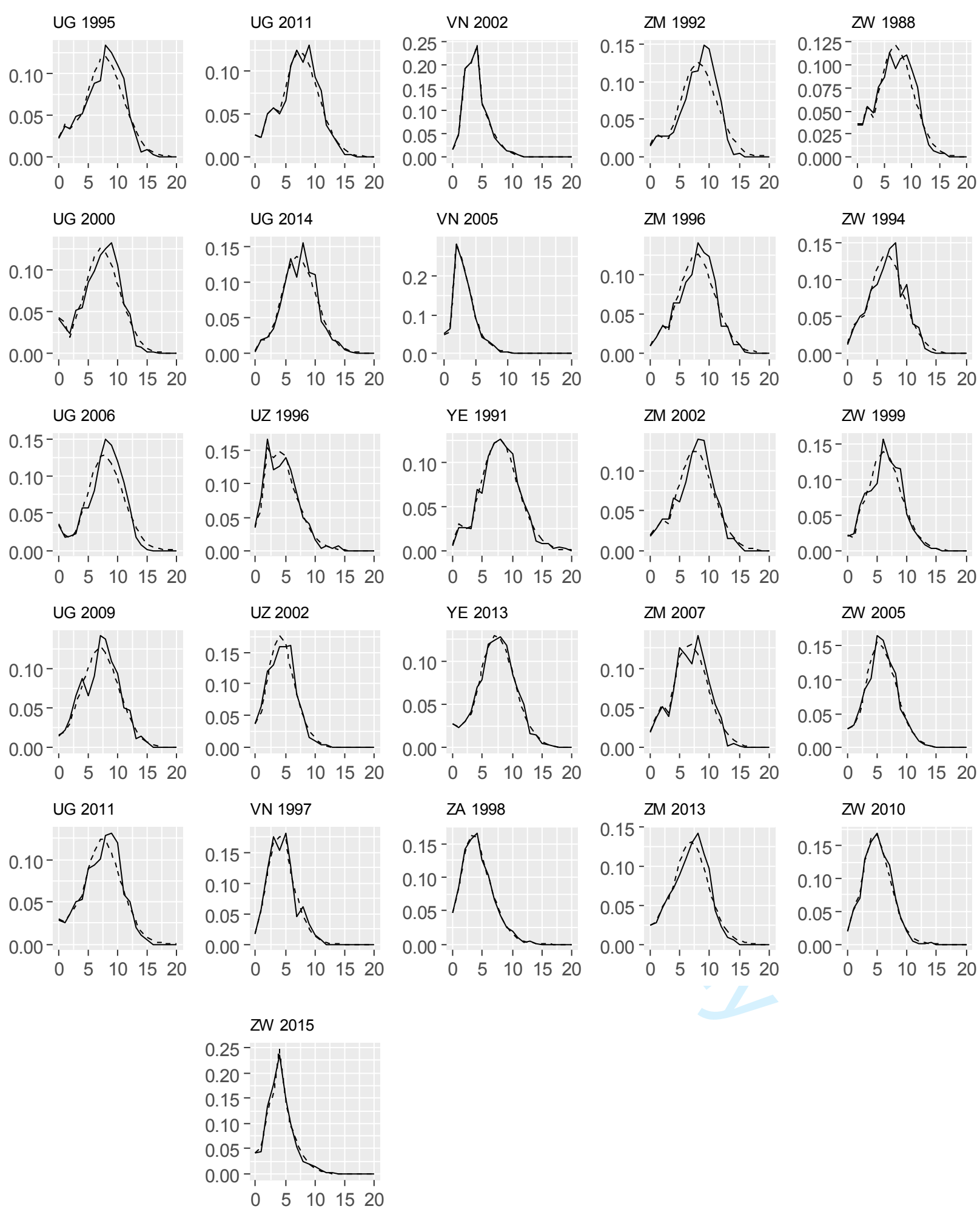